\title{
Numerical Modelling of the In-Nozzle Flow of a Diesel Injector with Moving Needle during and after the End of a Full Injection Event
}

\author{
Nikolaos Papadopoulos and Pavlos Aleiferis
}

University College London, UK

Copyright (C) 2012 SAE International

\section{ABSTRACT}

The design of a Diesel injector is a key factor in achieving higher engine efficiency. The injector's fuel atomisation characteristics are also critical for minimising toxic emissions such as unburnt Hydrocarbons (HC). However, when developing injection systems, the small dimensions of the nozzle render optical experimental investigations very challenging under realistic engine conditions. Therefore, Computational Fluid Dynamics (CFD) can be used instead. For the present work, transient, Volume Of Fluid (VOF), multiphase simulations of the flow inside and immediately downstream of a real-size multi-hole nozzle were performed, during and after the injection event with a small air chamber coupled to the injector downstream of the nozzle exit. A Reynolds Averaged Navier-Stokes (RANS) approach was used to account for turbulence. Grid dependency studies were performed with $200 \mathrm{k}-1.5 \mathrm{M}$ cells. Both $k-\varepsilon$ and $k$ - $\omega$ SST models were considered in the validation process, with the $k-\omega$ SST found to predict better the injector's flow rate. The cavitation models of Schnerr-Sauer and the Zwart-GerberBelamri were employed for validation against optical data of cavitation in a simplified nozzle geometry obtained from the literature. The Schnerr-Sauer model was in better agreement with the experiments, hence this model was subsequently employed for the real injector simulations. The motion of the injector needle was modeled by a dynamic grid methodology. An injection pressure of 400 bar was applied at the inlet of the injector. Two outlet pressures were examined, 60 bar and 1 bar. The results showed that the flow was far from steady-state during the injection event and that hysteresis existed between the needle opening and closing phases. This indicated the importance of transient simulations, contrary to widely-used steady state simulations at fixed needle lifts. The two outlet pressures resulted in very different final states of the flowfield in the nozzle. Specifically, the nozzle ended up either full of liquid fuel at the end of injection or full of air after most of the fuel had been ejected into the chamber downstream. These predictions highlighted phenomena that can increase HC emissions due to fuel leakage, as well as processes that may be linked to different formation mechanisms of nozzle deposits.

\section{INTRODUCTION}

\section{Background}

New regulations that constantly call for lower exhaust emissions, as well as international obligations to focus on sustainability, demand higher engine efficiency. Diesel engines are a source of air pollutants, with unburnt Hydrocarbons (HC) being particularly toxic. Unburnt $\mathrm{HC}$ mainly form due to poor air-fuel mixing and combustion. Under mixing can be caused by fuel that ends up on the cylinder and piston walls from spray impingement or from fuel that enters the chamber late in the combustion process with low velocity. A source of the latter form can be fuel which is coming out from the nozzle hole or nozzle sac volume after the end of injection and does not mix with air sufficiently [1]. Furthermore, after the end of combustion, increased temperatures may cause fuel that is left in the sac to evaporate and move towards the chamber through the orifice. The lighter compounds evaporate first, leaving back the heavier ones, which can create deposits inside the nozzle. Those deposits can harm the injector and reduce their life time as well as the engine's performance and efficiency [2] .

The injector can be designed with a smaller sac volume to reduce $\mathrm{HC}$ emissions. In Valve Covered Orifice (VCO) injectors the needle closes the nozzle's inlet so that fuel from the sac cannot enter the chamber. Such designs can minimize emissions [3] [4]. However, the presence of a sac is important to equalize to the pressure of the fuel at the nozzle inlets. A sacless injector typically produces poor quality sprays that can be different from each orifice of the same injector [5] [6]. The impact can be observed via different metrics, such as spray penetration, spray cone angle and rate of injection.

At real engine conditions, to promote atomization, Diesel fuel is injected with very high pressures, typically up to 2000 bar with values expected to increase even further in the future. It has been shown that under these conditions, cavitation appears inside the nozzle [7] [8], and vapour bubbles are formed. In addition, 'hydraulic flip' that is linked to in-nozzle flow 
separation at the orifice inlet that never reattaches upstream the nozzle exit, might occur and affect spray formation [6].

In the case of consecutive injections, bubbles of vapour have been noticed to exist inside the nozzle before the start of injection [9] [10]. These have a random pattern of distribution, with various sizes and at various locations and are thought to be created by cavitation in the last stages of the previous injection event. Those bubbles, given enough time, tend to coalesce and form one big vapour area that fills most of the sac's volume. Also, air is entrained inside the nozzle orifice from the outlet [10].

Apart from experimentation, in-nozzle flow insights have been obtained by Computational Fluid Dynamics (CFD) due to challenges associated with the faithful manufacturing of realsize optical nozzles with moving needles that could provide satisfying quantitative information. This has been done for both Diesel and gasoline injector geometries. The existence of vapour bubbles has been noticed in [11] and attributed to the inertia of the flow while the needle was still open; this caused the pressure inside the nozzle to drop abruptly when the needle closed, promoting cavitation. In [12] it was noticed that during the injection event, air entered the orifices through flow recirculation at the nozzle exit.

While most of the published studies of injection simulations employed computational domains that extended only up to the nozzle exit, some researchers have included a small part of the combustion chamber as well [13] [14] [15] This has been done in order to impose a boundary condition to the injector flow that could allow capturing the existence of hydraulic flip and also part of the ensuing spray. In such cases, most often, the Volume Of Fluid (VOF) model is used [12] [13] [16], which provides liquid-gas interface tracking. In combination with Large Eddy Simulation (LES) on a sufficiently dense grid, this method may also be able to predict the primary breakup [15] [17]. Also, other gases can be included in the calculation, such as air [12] [16].

Despite the transient flow and motion of the needle, it is common practice to simulate the flow as steady state at different fixed needle lifts [18] [19] [20] [21], or only at full needle lift [22]. Some work has been done on the effect of the needle's motion on the flow. For example [23] used a singlehole injector and simulated a $90^{\circ}$ sector of the real geometry due to periodicity. In contrast, [24] [25] used multi-hole injectors but, again, due to periodicity, only one orifice was modelled. Moving needle simulations that include a part of the injection chamber have also been performed. In [26] the injection chamber was modelled as full of liquid fuel, whilst in [27] an injection chamber full of air was used for the simulation of a pressure-swirl injector and in [28] a similar setup was used, in combination with VOF, to simulate the injection from a single-hole injector. It has been shown that the flow during the opening and closing stages of the needle's motion is transient, and hysteresis effects can take place [23] [25] [26]. However, in [29] no transient phenomena were Page 2 of 18 noticed, potentially due to the high inlet pressure, but there was a significant effect from the needle off-axis motion.

The flow at the end of injection has also been given some attention, due to its effect on performance and emissions. [30] performed X-ray radiography experiments to investigate the phenomena involved. [31] performed RANS simulations with a mixture multiphase model and compared their predictions to experimental results. Cavitation was noticed to occur after the closing of the needle as well as nozzle back-filling with ambient gas; there was also fuel dribble in the area near the nozzle exit.

\section{Present Contribution}

Despite a significant amount of background studies on innozzle flows, there is need for more information on simulations of a vertical multi-hole injector with a moving needle that has also incorporated a part of the combustion chamber filled with air as downstream boundary condition; this is to study aspects of in-nozzle phenomena both during the injection event and past the end of it. The work presented here includes transient Reynolds-Averaged Navier-Stokes (RANS) simulations of the full injection process as emerging through the geometry of a real-size multi-hole Diesel injector. The VOF multiphase model was employed. The focus was primarily on understanding the in-nozzle phenomena and not on simulating the spray formation process past the nozzle exit. The main objectives of the current work can be summarised as follows:

- To investigate the effect of the needle motion on the major characteristics of the in-nozzle flow, including the formation of vortical flow structures and cavitation during the injection event.

- To investigate the predictive effect of the presence of an air chamber downstream of the nozzle exit on the innozzle flow, particularly with respect to nozzle backfilling phenomena that can occur at the end of injection after needle closure and lead to simultaneous presence of liquid fuel, fuel vapour and air inside the nozzle.

- To study the effect of different 'back' pressure conditions (i.e. in-cylinder air pressure) on key characteristics of the in-nozzle flow, both during injection and after needle closure.

\section{METHODOLOGY}

\section{Mathematical Formulation}

Within the objectives of the current work, a commercial CFD code was employed that solves numerically the governing equations of fluid motion on a discretized computational domain by the finite volume methodology (Ansys Fluent) [32]. The flow under consideration was turbulent; a RANS formulation was employed for faithful approximation of the 
average quantities of the flow field and under no circumstances prediction of the jet breakup was sought after. Within this framework of study, two different turbulence modelling approaches were tested, the $k$ - $\varepsilon$ approach [33] [34] and the $k-\omega$ SST [35]. This was done because the geometry of study was associated with high pressure gradients and flow separation and reattachment effects that the $k-\omega$ SST is believed to handle more accurately than the $k-\varepsilon$.

\section{Multiphase Flow and Cavitation Models}

When two or more phases exist in a simulation, a multiphase formulation must be used to account for those. The intention of the present simulations was not to capture the interface of the bubbles within the nozzle, neither to obtain a sharp prediction of the liquid spray interface in the air chamber during the injection process, as this would require extremely dense grids and practically unrealistic running times. Instead, the main intention was to capture the liquid-air interface within the nozzle after needle closure and during backflow nozzle-filling events, e.g. to understand the formation of innozzle liquid film phenomena amongst other. Therefore, use of a VOF method was considered necessary [32]. With this methodology, when cavitation occurs and vapour appears inside the liquid continuum, this does not happen in the form of bubbles but as an average quantity inside the cell, similar to the mixture model behavior [32].

Specifically, in the Diesel injector under study, Diesel liquid, Diesel vapour and air were all considered present. VOF solves a continuity equation for the volume fraction of $n-1$ phases, with $n$ being the total number of phases present in the simulation, as follows:

$$
\frac{\partial}{\partial t}\left(\alpha_{q} \rho_{q}\right)+\nabla \cdot\left(\alpha_{q} \rho_{q} \boldsymbol{U}_{q}\right)=S_{\alpha_{q}}+\sum_{p=1}^{n}\left(\dot{m}_{p q}-\dot{m}_{q p}\right)
$$

where $\alpha_{q}$ is the volume fraction of phase $q, \rho_{q}$ is the density of phase $q$ and $\dot{m}_{p q}$ is the mass transfer from phase $q$ to phase $p$. $S_{\alpha_{q}}$ represents any source of phase $q$ that might exist. The phase that is not being solved for will be calculated based on the constraint that the sum of all volume fractions in a cell must be equal to 1 . The discretization scheme that was used for the solution of this equation was the Modified HRIC [32] [36].

The presence of cavitation was modelled by a mass transfer mechanism that converts the mass of a specified liquid to a specified gas (vapour). This happens when certain criteria are met, typically in this case, the condition is the local pressure. When the pressure drops below the vapour pressure, liquid is converted to vapour, while when the pressure rises again, vapour turns back to liquid. A sensitivity study was carried out between two cavitation models, the Schnerr-Sauer [37] and the Zwart-Gerber-Belamri [38]. Within the Schnerr-Sauer model formulation the vapour source term is:

$$
R=\frac{\rho_{v} \rho_{l}}{\rho} \frac{d \alpha}{d t}
$$

where:

$$
\alpha=\frac{n_{b} \frac{4}{3} \pi R_{B}^{3}}{1+n_{b} \frac{4}{3} \pi R_{B}^{3}}
$$

with $n_{b}$ being the number of bubbles in the volume of liquid (typically set as a constant of the order $10^{13}$ ) and $R_{B}$ is the bubble radius calculated by the Rayleigh-Plesset equation. In the Zwart-Gerber-Belamri model the vapour source term is calculated by:

$$
R=n\left(4 \pi R_{B}^{2} \rho_{v} \frac{D R_{B}}{D t}\right)
$$

where $n$ is the bubble number density.

Within the objectives of the current simulations for the specific injector geometry under study, the liquid density was assumed constant and the fuel vapour and air densities were calculated by the ideal gas equation of state. As will be detailed later, the inlet and outlet boundaries were set to a temperature of $300 \mathrm{~K}$. This was done partly because the experimental flow rate data that were available for validation had been obtained at this temperature. Another reason was that at higher temperatures evaporation and/or boiling could take place. These are complicated mass transfer phenomena that need appropriate sub-modelling features in the context of a faithful multi-phase calculation at high temperature. Implementation of the necessary submodels is currently work in progress by the current authors and investigation of the effects of such phenomena on the in-nozzle flow will be reported in a future publication. Table 1 summarises the properties of the liquid Diesel phase, vapour Diesel and air.

Table 1. Fluid properties used in the simulations.

\begin{tabular}{|l|l|}
\hline Liquid Density & $809.38 \mathrm{~kg} / \mathrm{m}^{3}$ \\
\hline Liquid Viscosity & $1.967 \times 10^{-3} \mathrm{~kg} / \mathrm{m} \cdot \mathrm{s}$ \\
\hline Vapor Pressure & $1000 \mathrm{~Pa}$ \\
\hline Surface tension & $0.02 \mathrm{~N} / \mathrm{m}$ \\
\hline Vapour Viscosity & $1.34 \times 10^{-5} \mathrm{~kg} / \mathrm{m} \cdot \mathrm{s}$ \\
\hline Air Viscosity & $1.79 \times 10^{-5} \mathrm{~kg} / \mathrm{m} \cdot \mathrm{s}$ \\
\hline
\end{tabular}

\section{Injector Geometry}

The geometry of a real, vertical multi-hole injector with sac volume was used. The total length of the geometry in the direction of the axis of the needle is $7 \mathrm{~mm}$. There are 7 orifices with a length of $0.6 \mathrm{~mm}$ and diameter of approximately 0.12 
$\mathrm{mm}$. The inlet curvature radius is $0.02 \mathrm{~mm}$, resulting in an $r / D$ ratio equal to $1 / 6$, and the inclination angle is $84^{\circ}$. The periodicity of the geometry allowed the use of only one sector with one orifice, in order to save computational time. The geometry is illustrated in Figure 1.

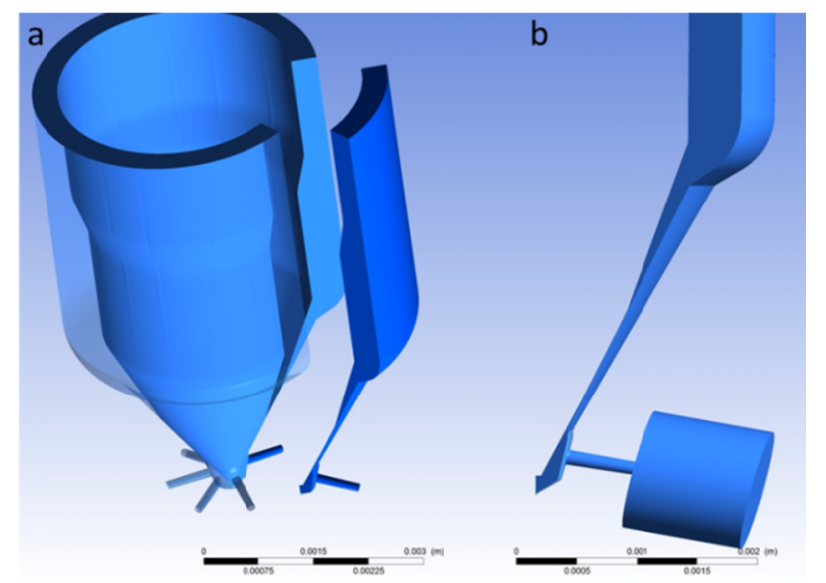

Figure 1. a) Geometry of the multi-hole injector. b) Sector of a single hole with air chamber attached.

In order to allow simulations of the fluid motion after the end of injection an extra volume (of length equal to 10 nozzle diameters), considered to be a part of the combustion chamber, was attached to the nozzle exit (Figure 1). A similar method has been used in [14] [26] as an approach to providing more accurate pressure boundary conditions, but the interior of the chamber was set to be full of liquid. The studies of [13] [16] [15] [27] have used a chamber full of air as initial condition in order to investigate the flow in the vicinity of the nozzle outlet and partial hydraulic flip.

\section{Boundary and Initial Conditions}

The boundary and initial conditions of the simulations are summarized as follows:

- A pressure inlet, where the total pressure was constant and set to 400 bar for all simulations. The liquid volume fraction at the inlet was 1 .

- Static pressure at the outlet, which consisted of the circumferential side and the bottom side of the added air volume. Two different values of pressure were used and compared, 60 bar and 1 bar absolute pressure.

- The injector body, including the orifice and the top side of the attached volume were set as no-slip walls.

- The sides of the geometry were periodic boundaries. Within the objectives of the current RANS work, such an approach can provide a satisfying description of the flow field in the nozzle hole. However, in practice this approach may not be always realistic [39], so for more detailed simulations, e.g. when adopting LES, use of such periodic conditions would need to be reconsidered via sensitivity analysis.
- All the walls were considered adiabatic. The inlet and outlet boundaries were set to a temperature of $300 \mathrm{~K}$.

- At the beginning of the simulation, the flow field was considered to be at rest. The nozzle was full of liquid fuel, while the injection chamber was full of air.

\section{Mesh and Needle Motion}

For the simulations performed, a moving mesh strategy was used by adopting the layering technique [32]. Specifically, the computational domain consisted of two regions. One was the non-moving region, which was actually the geometry when the needle was at its fully closed position. The moving region was made out of the volume that was created as the needle moved. When the needle moved, the layer of cells in touch with the needle changed size in order to account for this motion. When the size of those cells exceeded certain limits, the cells either divided into smaller ones, thus creating a new layer, or combined with the neighboring layer. The needle was a moving no-slip wall boundary. Practically, for all simulations, the needle never actually touched the needle seat. This is because the code cannot handle two different wall boundaries when these touch. In order to seal the highpressure zone from the sac and nozzle area at needle closure, a wall interface was enabled. Specifically, there was an interface that connected the needle seat area with the needle throughout the whole simulation. While the needle was in motion, this interface was considered "interior", so it had no effect on the flow. However, just before the start of the needle's motion, or when the needle descended to $0.5 \mu \mathrm{m}$ lift, this interface was switched to "wall"; this then resulted in two disconnected domains [31], interrupting the flow passing through and sealing the high-pressure from the low-pressure zone. During the period that this interface was defined as wall, it consisted of 4 cells in thickness.

The needle lift curve is illustrated in Figure 2. This defined how the needle moved with respect to time after the start of injection. Compared to the maximum lift of $256 \mu \mathrm{m}, 0.5 \mu \mathrm{m}$ was considered negligible. The injection duration was $1.86 \mathrm{~ms}$ long, during which the needle was ascending for $0.88 \mathrm{~ms}$ and descending for $0.98 \mathrm{~ms}$.

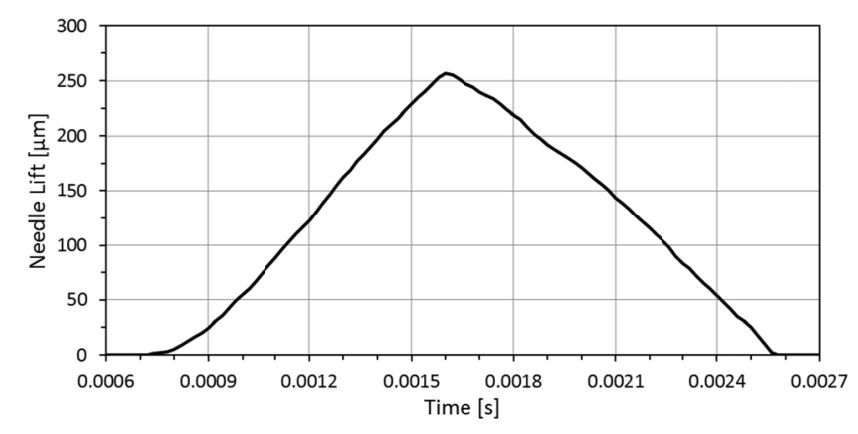

Figure 2. Needle lift curve. 
A block-structured mesh was used for the discretization air domain. Aim of the mesh generation procedure was a fine boundary layer resolution, both inside the orifice and at all the wall boundaries upstream of it. The achieved wall $\mathrm{y}^{+}$was always less than 1 in the region of the sac and nozzle orifice. Details of the mesh are shown in Figure 3. When the needle was closed, the mesh consisted of 611,478 cells, 391,878 of which were part of the nozzle, while the rest were part of the chamber. At full lift there were 1,130,094 cells in total. 50 cells were typically placed along the nozzle diameter. At the core of the orifice the cell size was $\sim 4 \mu \mathrm{m}$, while the first cell at the wall was $\sim 0.15 \mu \mathrm{m}$. The average size at the sac area was also $\sim 4 \mu \mathrm{m}$.

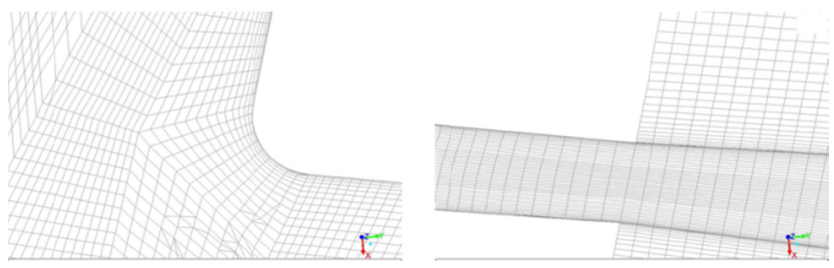

Figure 3. Details of the mesh at the orifice inlet and outlet areas.

For grid sensitivity analysis, three more meshes were created and tested. A coarse one, with 120,000 cells at minimum needle lift (excluding the extra air volume), a medium one with 250,000 cells and a very fine mesh with $1,500,000$ cells. The predicted volumetric flow rate throughout the whole injection event was very close with all four meshes, with a maximum difference of $0.5 \%$ between the coarse and very fine mesh. Figure 4 compares the velocity profile of the four meshes along a diameter at the orifice inlet (X co-ordinate), where flow separation and recirculation was found to occur. The pressure boundary conditions were 400 bar inlet, 60 bar outlet with the $k-\omega$ SST model. Second-order discretisation was employed for this exercise, as well as for all the results to be presented thereafter.

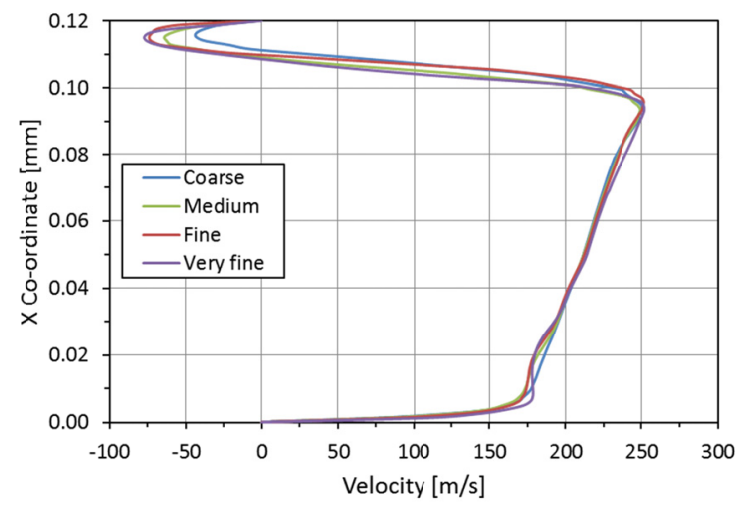

Figure 4. Velocity profile at orifice inlet.

The length of the recirculation zone was calculated for all meshes and the result is shown in Figure 5. The difference between the fine and the medium mesh was of the order of $4.6 \%$, while for the fine and the very fine it was $2.1 \%$. The

Page 5 of 18 very fine mesh was not considered practical within the limitations of the available computational power, as it was much more computationally demanding without providing respectively higher detail. For this reason, the rest of the simulations in this paper were performed with the fine mesh.

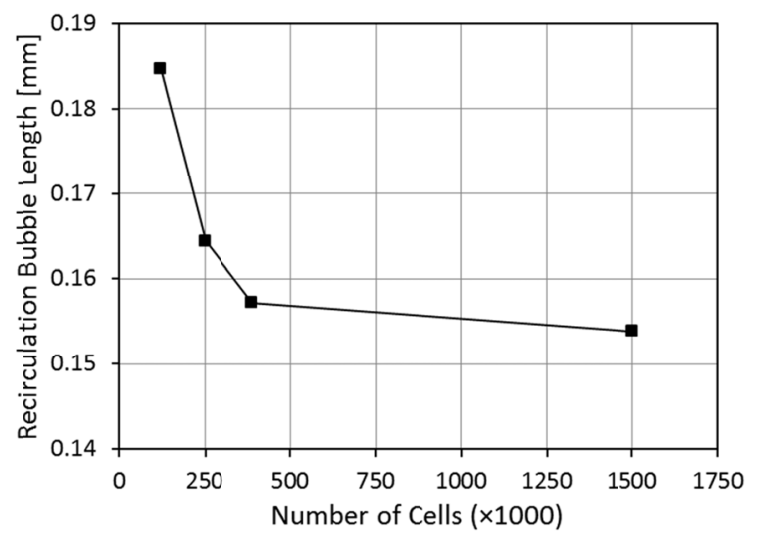

Figure 5. Length of recirculation zone.

\section{VALIDATION}

Validating in-nozzle flow simulations can be a quite challenging process, especially under realistic injector conditions. This challenge is primarily associated with the lack of available data, particular of optical nature and of quantitative type from faithful real-size optical injector nozzles. Two different validation processes of the suggested methodology were finally selected and performed within the bounds of the current work. The first one aimed at studying the flow rate during the injection process and comparing this against measured flow rate data to study the effect of turbulence model. The second one was based on a published study of cavitation in an optical nozzle obtained from the literature. This aimed at comparing the cavitation pattern under different conditions with the two cavitation models.

\section{Injector Flow Rate}

The volumetric flow rate at the injector's inlet during a whole injection cycle is illustrated in Figure 6. This figure compares the experimental data (obtained by volume flow rate measurements at the injector line upstream of the injector) to the computational results for inlet pressure of 400 bar and outlet pressure of 60 bar with the $k-\varepsilon$ and $k-\omega$ SST models. This combination of inlet-outlet pressures was selected because these were the only conditions at which measured flow rate data were available for this particular injector geometry, therefore only these conditions could enable direct comparison between simulations and experiments. Three different timings, termed $1^{\text {st }}, 2^{\text {nd }}$ and $3^{\text {rd }}$ time instance, are illustrated in Figure 6. These are the timings at which contours of in-nozzle liquid volume fraction and velocity vectors are shown and discussed later in the results section. They correspond to needle lifts of $25 \mu \mathrm{m}$ during the needle opening 
period, maximum lift of $\sim 250 \mu \mathrm{m}$ and $25 \mu \mathrm{m}$ during the needle closing period (see Figure 2).

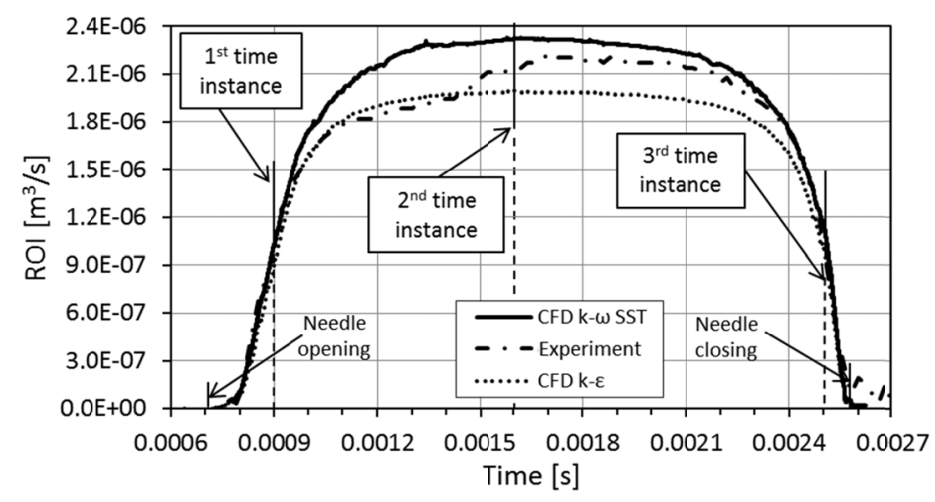

Figure 6. Volumetric flow rate at the inlet of the injector throughout injection.

A satisfying agreement with the experimental data is noticed at the very early stages of needle opening and at the latest stages of closing with the $k$ - $\omega$ SST model. During the period that the flow rate is independent of the needle lift, however, a difference between the experimental and computational $k-\omega$ SST line is observed. This is particularly noticeable at the first half where the needle lift increases. In contrast, the $k$ - $\varepsilon$ model seems to predict better the flow rate for most of the early stages of injection but then under-predicts the rate past maximum needle lift.

This behaviour was considered carefully and it is believed that that reasoning behind these observations can be associated directly with the fixed inlet pressure boundary condition of 400 bar that was used in the simulations. In practice, this fixed value is likely to vary from the actual pressure at the inlet of the injector during the early stages of injection. When the needle starts lifting, a pressure drop is typically noticed on the injector's fuel line, which recovers later in the injection process. Therefore the measured flowrate exhibits an asymmetric profile when comparing pre- and post- maximum needle lift periods, clearly indicating a slower rate on the early period. Unfortunately, the line pressure of the experiment was not available. Therefore, data from the literature were used to study potential effects. Specifically, the line pressure from [10] was used to draw conclusions because the respective flow rate was very similar to the one of the current study. The line pressure of [10] dropped abruptly at the beginning of the injection by $\sim 13 \%$ of the nominal value and did not recover completely till the end of injection. In the spirit of this observation, a test simulation with a pressure inlet of 360 bar, i.e. $10 \%$ lower than the nominal of 400 bar, was performed. The resulting flow rate was found to match the flow rate of the experiment in the first half of the injection event (shown in Figure 6) with tolerance of $\sim 5 \%$. A similar type of behaviour has been noticed in [40] and [41]. Moreover, the computational work of [12] also used a constant pressure inlet and the resulting flow rate was similar to the one shown in Figure 6. With such pressure fluctuations in mind, the difference between the experimental and computational volume flow rate, can be considered to be within $3 \%$ throughout the whole duration of the injection, based on the second half of the simulation, where the needle was descending. More to the point, the $k$ - $\varepsilon$ turbulence model that appeared to be in better agreement with the experimental results in the first part of the simulation in Figure 6 would produce a much lower volume flow rate with the use of a correct varying inlet pressure at the early stages. Close up study of the in-nozzle flow field predictions of the $k$ - $\varepsilon$ model also revealed much different recirculation zones than those predicted by the $k$ - $\omega$ SST model which could be directly linked to the different discharge coefficient implied by Figure

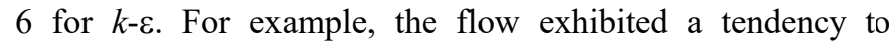
remain attached to the wall both at the orifice inlet and at the nozzle outlet where the liquid jet emerged. Therefore, finally the $k$ - $\omega$ SST was considered more appropriate for this application and it was employed throughout the rest of the simulations. For completeness it is mentioned that the predicted flow rate curve of the the $k$ - $\omega$ SST model was independent of cavitation model; both the Schnerr-Sauer and the Zwart-Gerber-Belamri models led to identical flow rates as this case was associated with almost no presence of cavitation (as will be discussed in detail later).

\section{Optical Nozzle Study}

The experimental work of [42] has been used by some authors to validate simulated cavitating flows. However, conflicting observations have been reported. For example, it was found in [43] that the Schnerr-Sauer model underestimated the size of the cavitation zone but it matched better the velocity profiles than the Zwart-Gerber-Belamri. Therefore, it was decided to identify a different optical geometry with sufficiently rich data that could be used for validation. After extensive survey, the experimental optical geometry of [44] was finally selected. This was done because [44] offered all necessary dimensions to faithfully model their optical nozzle, as well as a multitude of experimental data at different Reynolds numbers and fluid temperatures to compare with. Temperature effects may not be directly relevant to the Diesel injector simulations presented in the current paper, but as mentioned earlier, studies at different temperatures form part of our work in progress, hence [44] was considered useful to validate the methodology over a range of fluid temperatures too.

The geometry of [44] was a quasi-2D nozzle of $4 \mathrm{~mm}$ width, so a two-dimensional mesh was created. The computational domain extended 10 times the width upstream of the nozzle inlet and downstream of the nozzle exit. The mesh consisted of 15,825 cells with 50 cells employed across the nozzle's width. By varying the inlet velocity and the fluid's temperature (and consequently viscosity, vapour pressure, etc.), the effect of Reynolds number and temperature on the length of the cavitation zone was investigated and compared to the experimental results. Figure 7(i) illustrates contours of the predicted liquid volume fraction distribution produced by the

Page 6 of 18 
Schnerr-Sauer model and directly compared to images taken from [44]. Clearly, good agreement is observed. To bring this behaviour in quantitative context for both models, Figure 7(ii) depicts the variation of the non-dimensional length of the cavitation zone over the nozzle length, $l^{*}$, for both cavitation models, Schnerr-Sauer and Zwart-Gerber-Belamri, in direct comparison to the experiments. In this figure, both models agreed with the experiments at $R e=50,000$ and predicted no cavitation as also observed in the experiment. Good agreement is also seen at the highest Reynolds number of 70,000. Between those two limits, both models appeared to overpredict the cavitation length. However, the Schnerr-Sauer model was clearly better and closer overall to the experiment, following mostly the same trend all over the range of tested Reynolds numbers. The Zwart-Gerber-Belamri deviated far from both the experiment and the Schnerr-Sauer model at $R e=64,000$.
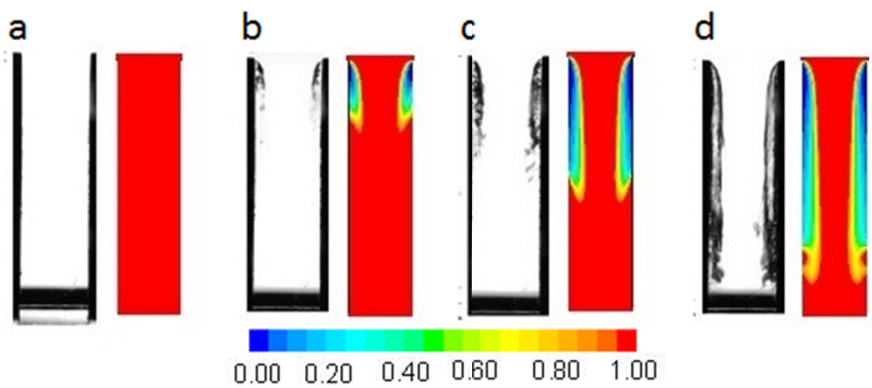

(i)

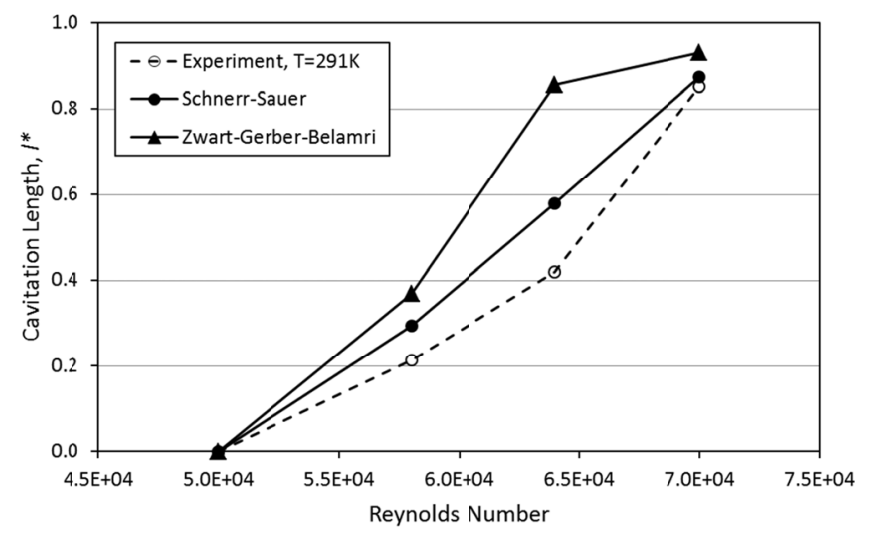

(ii)

Figure 7. (i) Predicted liquid volume fraction distribution compared to images acquired by [44] for a) $R e=50,000$, b) $R e=58,000$, c) $R e=64,000$, d) $R e=70,000 . T=291 \mathrm{~K}$.

(ii) Comparison of cavitation zone length measured in [44] and predicted by the two cavitation models.

Therefore, the Schnerr-Sauer model was considered more appropriate as a whole and further study was performed with this at different temperatures. The results are plotted in Figure 8 . For $T=303 \mathrm{~K}$ the results are very close except for the low Reynolds numbers, where a different cavitation initiation point was captured. Overall, there are areas with very good agreement (less than 5\% difference), but there are also areas Page 7 of 18 where the predicted cavitation zone length is further away from the respective obtained by experimentation. At $T=333 \mathrm{~K}$ the difference reaches its widest at $\mathrm{Re}$ in the region of 130,000 . Some of those differences can be explained by differences in the properties of the liquid used. The authors of [44] used tap water which can have different behaviour to pure water used in the simulations. However, it can safely be said that all the curves follow very similar trends and that the difference in the Reynolds number of cavitation initiation and super-cavitation was always less than about $10 \%$. For completeness, it is noted that the mixture model [32] was also tested in this validation case, giving results on the length of the cavitation zone within 5\% of the VOF model predictions.

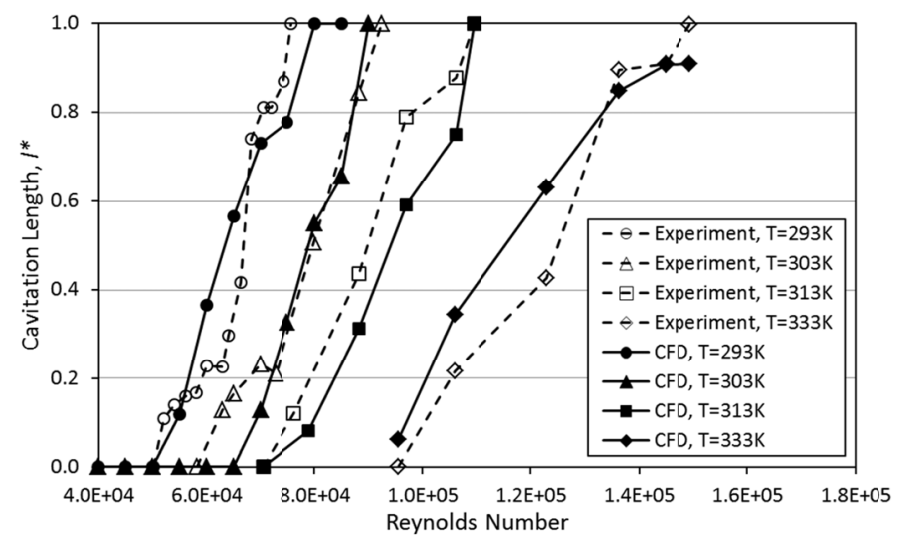

Figure 8. Effect of Reynolds number on the length of the cavitation zone.

\section{$\underline{\text { RESULTS }}$}

Two simulations were run, with two different ambient pressures. One with high pressure, equal to $60 \mathrm{bar}$ absolute, that corresponds to the condition also used in the validation section discussed earlier. The second was with a low pressure outlet of 1 bar absolute. The following sections present and discuss results of these simulations. Contours of liquid fuel volume fraction and velocity vectors are shown for three different time instances during the injection event. These instances have been defined in the graph of the injector's flow rate presented earlier in Figure 6; they were also brought into perspective with the motion of the needle shown in Figure 2. The first timing is approximately $0.2 \mathrm{~ms}$ After the Start Of Injection (ASOI). At that point the needle lift is $25 \mu \mathrm{m}$ and the flow is accelerating. The second one is approximately at the middle of the injection procedure, at maximum needle lift, $\sim 250 \mu \mathrm{m}$. Normally at this point the flow rate remains constant and the flow can be considered of steady state. The last time instance is approximately $0.1 \mathrm{~ms}$ before the end of injection, at $25 \mu \mathrm{m}$ needle lift, i.e. just about before needle closure. This timing corresponds to an abrupt deceleration of the fluid, thus abrupt drop in pressure. Contours for the period After the End Of Injection (AEOI) till the point where the flow was considered to have been brought to a halt, are also shown. 


\section{High-Pressure Outlet (60 bar)}

Considering that the injection pressure $p_{i n j}$ was 400 bar, the air pressure $p_{a m b}$ was 60 bar and the vapour pressure $p_{v}$ was 1000 $\mathrm{Pa}$, the cavitation number for this case was calculated to be $C N=\frac{p_{i n j}-p_{a m b}}{p_{a m b}-p_{v}}=5.66$ whilst the cavitation index was calculated as $K=\frac{p_{i n j}-p_{v}}{p_{i n j}-p_{a m b}}=1.18$. The Reynolds number based on the mean velocity at the nozzle exit was found to be equal to $R e=\frac{\rho_{\text {fuel }} U_{\text {exit }} D}{\mu_{\text {fuel }}}=10,500$ and the discharge coefficient of the nozzle was calculated by the simulations to be $C_{d}=0.7327$.

\section{$\underline{\text { In-Nozzle Flow during Injection }}$}

The predicted flow during the injection with high-pressure outlet is shown in Figures 9 and 10 that depict liquid volume fraction contours and velocity vectors, respectively. At $0.2 \mathrm{~ms}$ ASOI the tip of the liquid jet has already reached the end of the computational domain in Figure 9. The liquid core (where liquid has volume fraction of 1) ends halfway from the nozzle exit to the boundary of the computational domain. There exists a region of lower liquid volume fraction that corresponds to the breakup area and represents the region where fuel ligaments should be in real life. There are also some fluctuations on the external side of this region, suggesting instabilities that are known to exist on the surface of the liquid jet in the area downstream of the nozzle exit. No cavitation can be seen at the nozzle-hole entrance or at any other place in the flow domain.

At maximum needle lift, the flow appears to be of steady state. There are a few differences between this time instance and the first one. Still no cavitation can be seen within the domain. No fluctuations were depicted at the boundaries of the fuel jet. The liquid core has now reached the end of the computational domain.

Finally, the flow field at $0.1 \mathrm{~ms}$ before the end of injection is very similar to the first one in terms of liquid volume fraction. The fluctuations are back, indicating that this was not just an effect of the initial conditions but an actual state of the flow that was resolved. The liquid core again starts moving backwards, resembling the beginning of the injection. There is also a faint sign of cavitation at the nozzle entrance region just by the wall. This is a very small area though, and no vapour is carried downstream. Upon close inspection it was found that cavitation appeared 'randomly' in that region throughout the whole duration of the injection event. The lowest pressure in the whole domain was located there and was marginally equal to the vapour pressure. The pressure increase immediately downstream did not allow vapour to be seen on vertical planes.

This very weak presence of cavitation under these flow conditions seems to be in agreement with the findings of [45].

Page 8 of 18
Specifically, [45] highlighted on the typical graph of discharge coefficient $C_{d}$ versus cavitation index $K$ that the region of $C_{d} \sim 0.73$ and $K \sim 1.2$ corresponded to an area of flow transition from non-cavitating to cavitating conditions. The work of [45] was based on nozzles that had inclination angle of $84^{\circ}$ and $r / D$ that varied in the range of $0-1 / 4$, i.e. similar values to those of the nozzle used in the current study.

The velocity vector plots of Figure 10 illustrate secondary flow patterns inside the nozzle hole and indicate the development of vortical structures. At the needle opening stage, there are two counter rotating vortices that enter the nozzle hole from the sac.

This type of flow structure has also been reported in [24] and [41] with higher Reynolds numbers, in the area of 70,000 and 50,000 respectively, and assumed to be responsible for the formation of string cavitation. Both these vortices are linked with the sac volume. The results here do not indicate the existence of such type of cavitation though. It has been suggested in [41], however, that string cavitation cannot be captured by existing cavitation models as this type of cavitation is very complex and may occur dynamically at local pressures that may be higher than the vapour pressure. There is also separation of the flow at the same location, and a recirculation zone that is not clearly visible because it interacts with the aforementioned vortices. Downstream of the entrance, a system of four vortices has been created that seem to be rotating around the orifice axis. Further downstream, at the nozzle exit, the vortices appear to have faded away.

Later, at the middle of the injection, where the flow conditions are quasi-steady, the flow separation zone can be observed again. The two vortices entering the nozzle hole are now located at the bottom of the orifice. It looks as if downstream these two induce the creation of the vortex pair that is located at the top of the orifice. The system of these four vortices extends outside the nozzle now, dominating the flow in the spray region.

Finally, at the needle closing stage, the vortical structures resemble those that appeared during the opening stage. At this time two more vortices can be seen in the sac area. They are located one on top of the other, with their axes perpendicular to the symmetry plane (or in the circumferential direction); as expected, they are counter-rotating. The velocity field inside the orifice is also slightly different, with velocities of higher magnitude appearing at this stage.

This behavior is attributed to hysteresis effects, as also reported in [23] [25] [26], despite the fact that no cavitation is present. These published studies used a needle lift curve with duration of the order of 1.5-2.0 ms and maximum needle lift of the order of $250 \mu \mathrm{m}$, i.e. similar to the current study. However, their cavitation numbers varied in the range of 4150 and their injection pressures were in the range of $8-1500$ bar. 
Liquid Volume Fraction

T $\begin{aligned} & 1.0 \\ & 0.9\end{aligned}$

0.8

0.7
-0.6

$-0.5$

$-0.4$

0.3

0.2
0.1
0.0

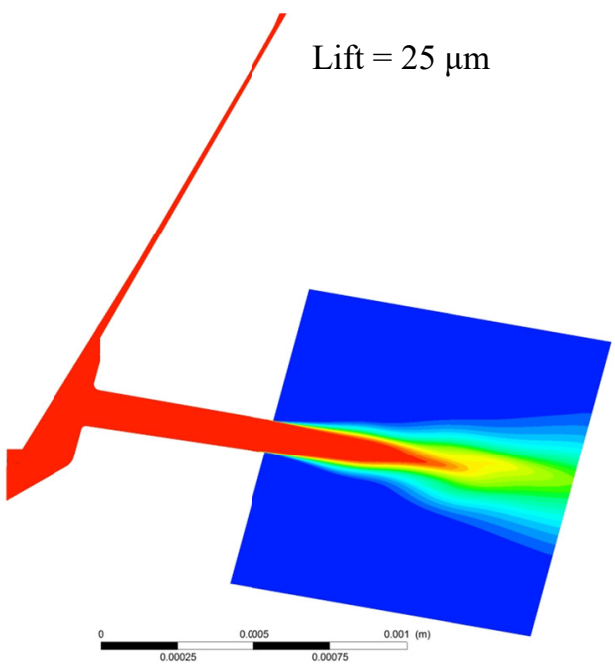

Time $=0.000901[s]$

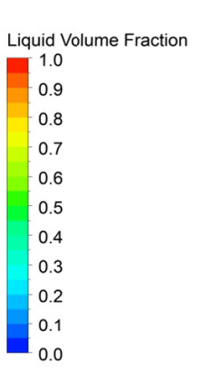

Time $=0.001606[s]$
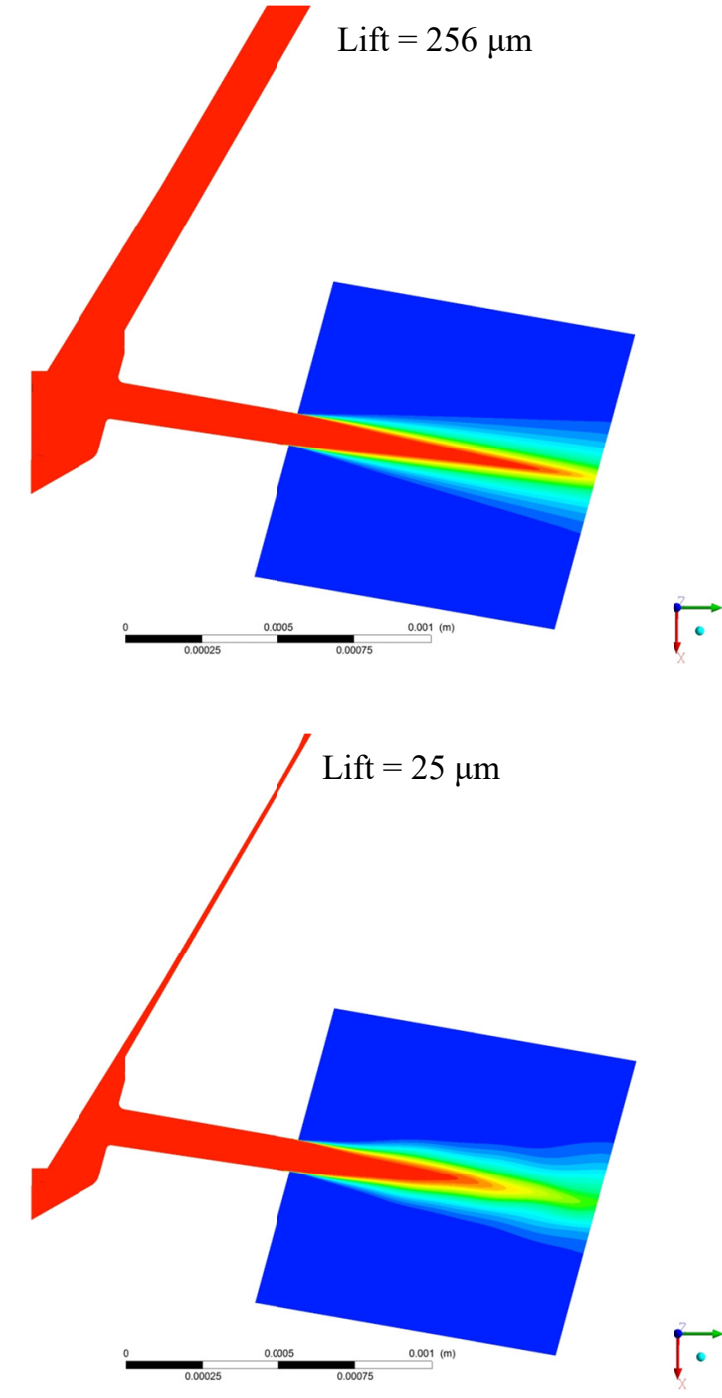

Time $=0.002501[\mathrm{~s}]$
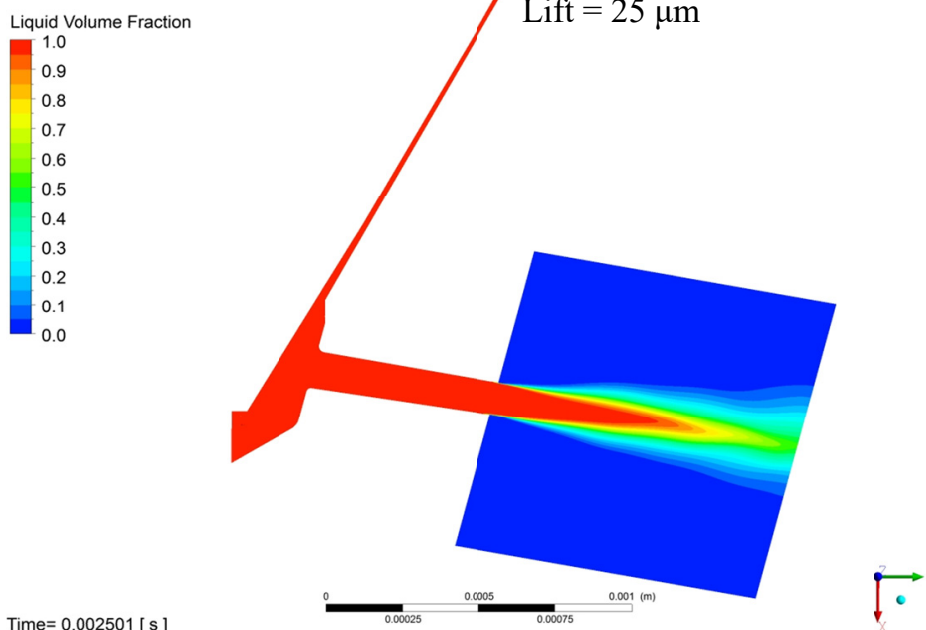
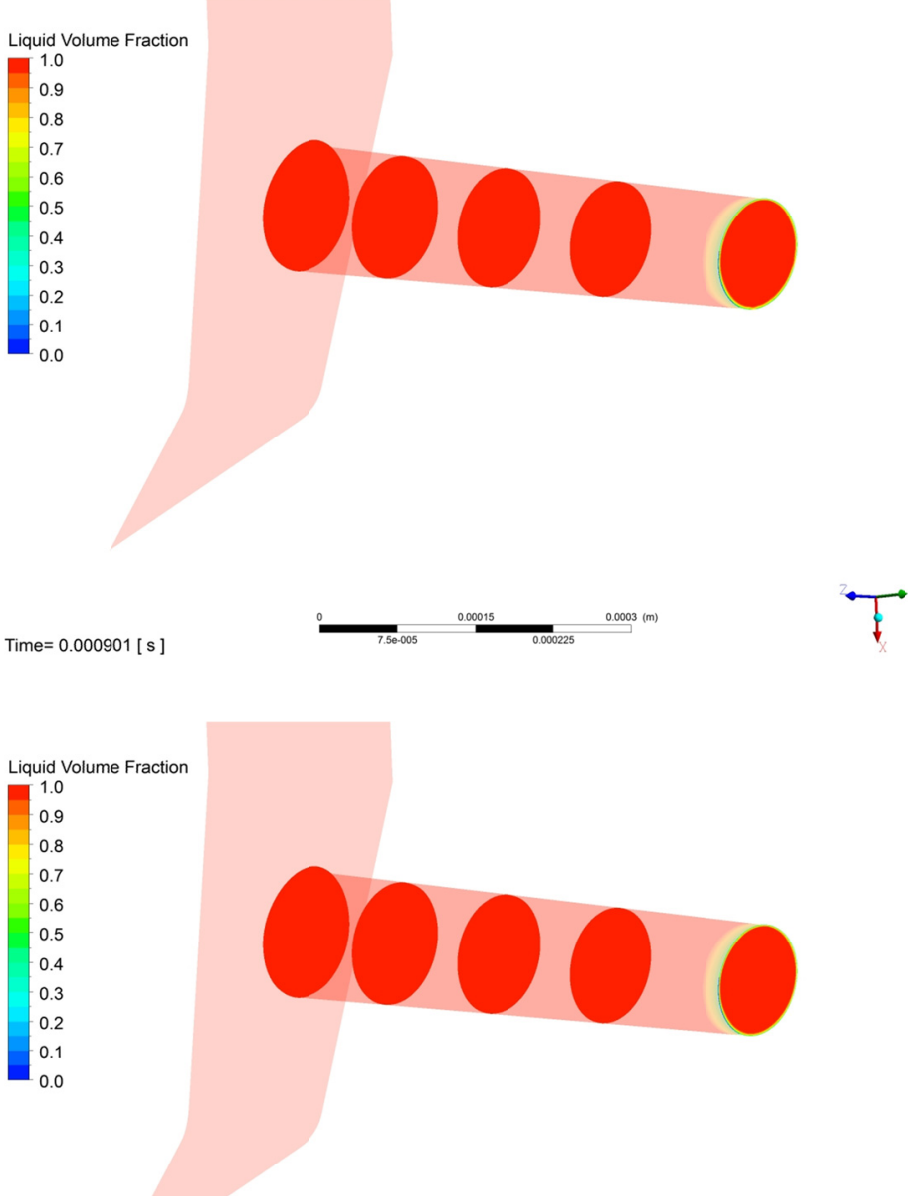

Time $=0.001606[s]$
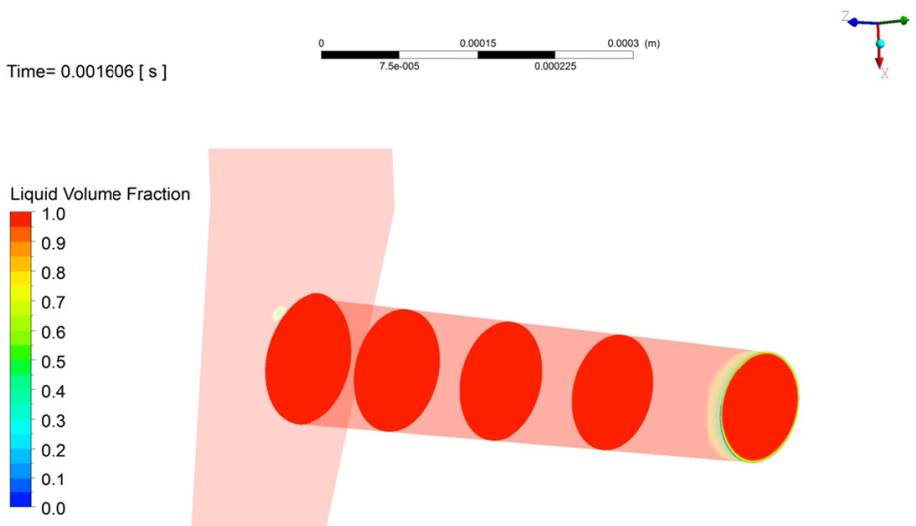

Time $=0.002501[\mathrm{~s}]$
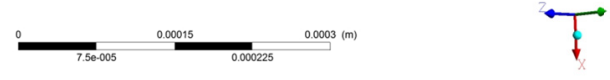

Figure 9. Liquid volume fraction for three time instances with ambient pressure 60 bar.

Page 9 of 18 

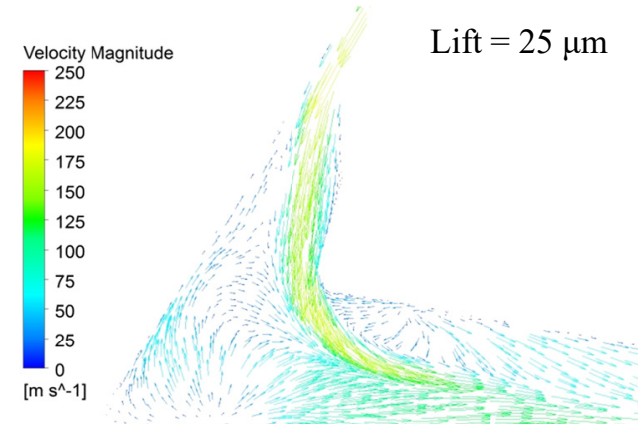

$x_{1}$

Time $=0.000901[\mathrm{~s}]$
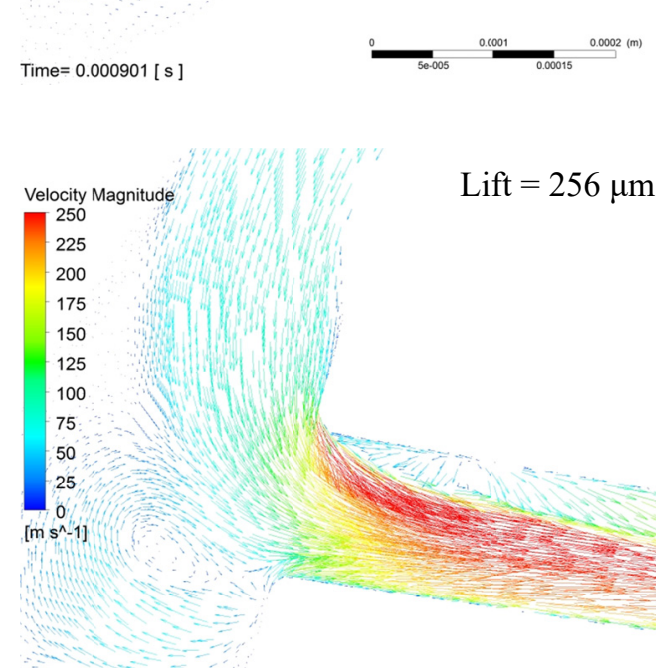

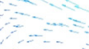
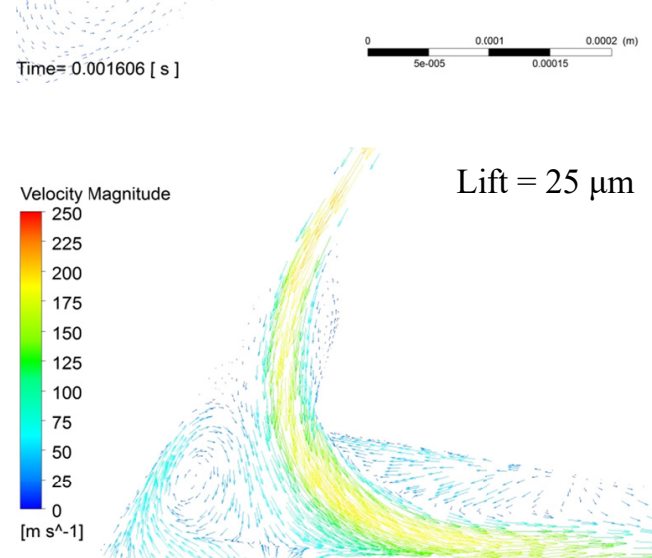

Lift $=25 \mu \mathrm{m}$

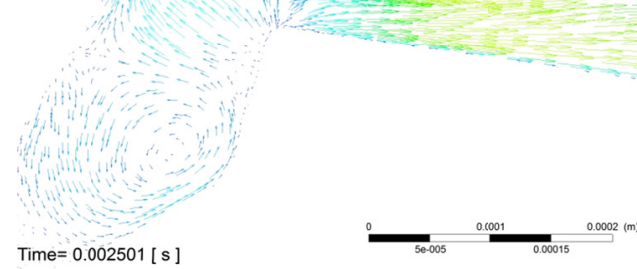

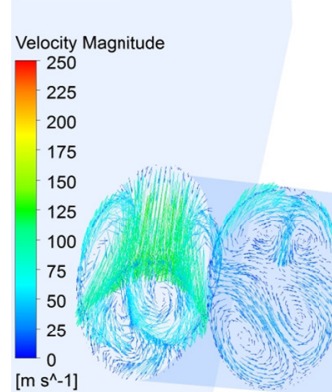

$\left[\mathrm{m} \mathrm{s}^{\wedge}-1\right]$

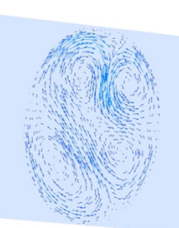

$\frac{0.560 .005}{750.005}$

Time $=0.000901[s$ ]

Velocity Magnitude

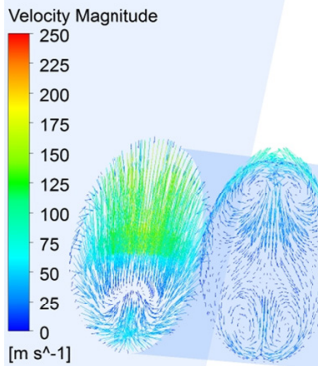

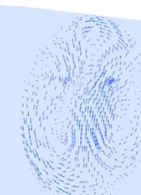
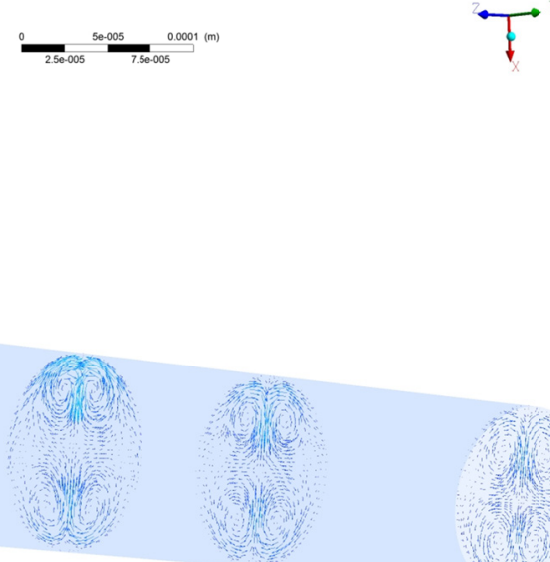

50
25
0
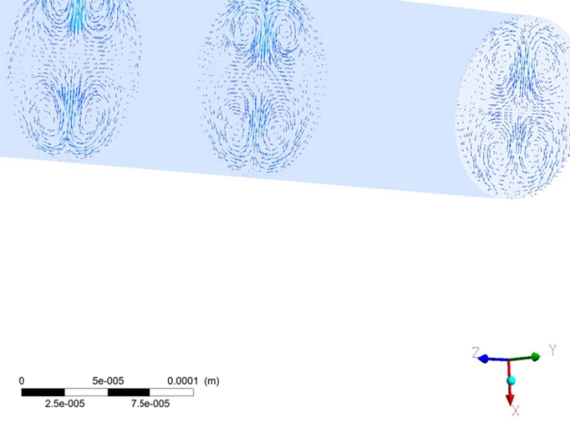

Time $=0.001606[\mathrm{~s}$ ]

Velocity Magnitude

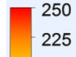

225

$-175$

175
-150

$-125$

-100
-75

75
50

[m $s^{\wedge}-1$ ]
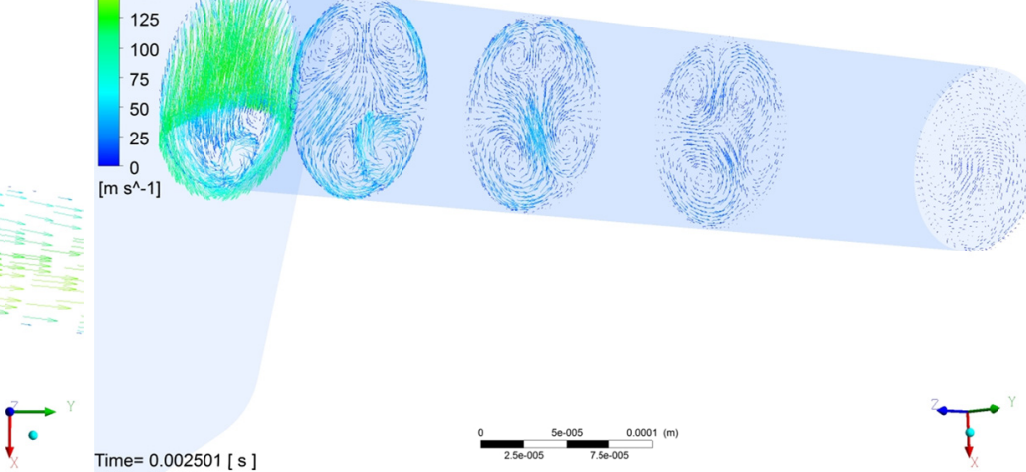

Time $=0.002501[\mathrm{~s}]$

Figure 10. Velocity vectors tangential to the displayed planes, for three time instances with ambient pressure 60 bar.

Page 10 of 18 


\section{In-Nozzle Flow after the End of Injection}

At the last stages of the needle's closing period, the flow decelerates and in the end it is brought to a halt. This change in the dynamic state of the liquid is accompanied by a change in the pressure field. Upstream of the needle seat, the pressure increases abruptly, while downstream it drops. This is caused from inertia, as explained in [11]. Therefore, the higher the inertia of the flow, the lower the pressure drop. In addition, the ambient pressure is the stabilizing factor around which the pressure field will oscillate. In the case under consideration, the ambient pressure is 60 bar, which is considerably higher than the vapour pressure. So despite the pressure drop in the sac and orifice area, the pressure difference is not enough for the fluid continuum to rupture and no cavitation was observed. Figure 11 illustrates the liquid volume fraction and Figure 12 illustrates the corresponding velocity magnitude at the last stages of simulation. The fluid motion inside the nozzle stopped at approximately $20 \mu$ s after the end of injection and the nozzle remains still full of liquid fuel.

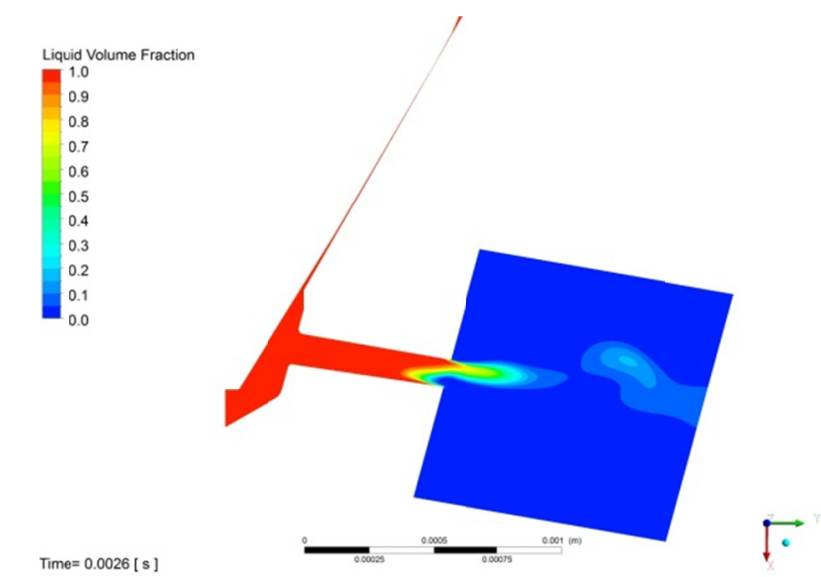

Figure 11. Liquid volume fraction of the final instance of the flow field, 60 bar outlet.

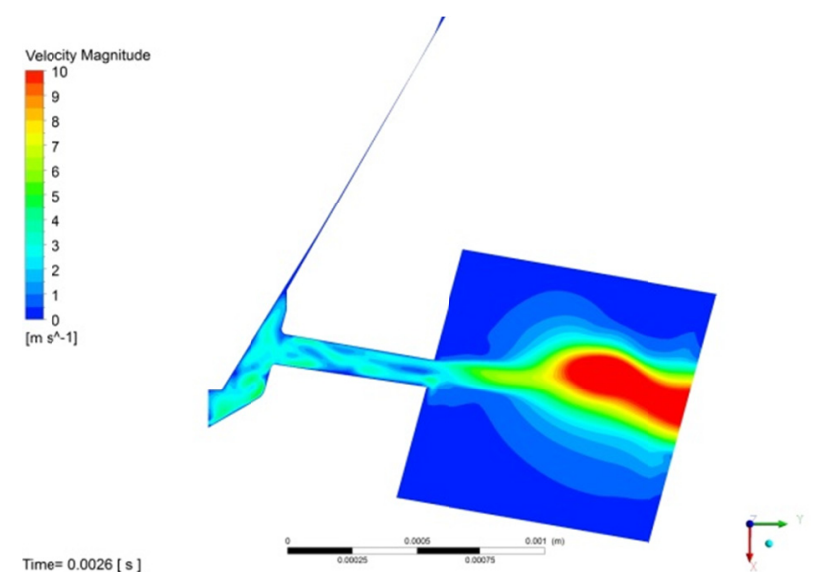

Figure 12. Velocity magnitude of the final instance of the flow field, 60 bar outlet.

The timing of those figures was selected to be such at which the velocity magnitude everywhere inside the nozzle had dropped to values below $3 \mathrm{~m} / \mathrm{s}$. This was an arbitrary value Page 11 of 18 but, to put it into context, at this velocity the time required for fuel to travel the distance of one diameter would be approximately $40 \mu \mathrm{s}$ which was considered very small in comparison to the duration of the whole injection of $\sim 2 \mathrm{~ms}$. In any case, it is also clearly noted that there appears to be a small quantity of fuel still dripping out of the nozzle. This may well contribute to $\mathrm{HC}$ emissions due to its low velocity and inability to mix with air appropriately. Additionally, although the internal nozzle flow has essentially stopped at this stage, the remaining fuel in the hole is still prone to ejection at a later stage of the engine cycle or to evaporation effects. Specifically, at real engine conditions, increased temperature and pressure conditions later in the cycle, and/or higher gas velocity in the combustion chamber formed by the piston's motion between injections can have a profound effect on how this remaining volume of liquid fuel in the nozzle will behave. This requires further study.

\section{Low-Pressure Outlet (1 bar)}

The same setup was used as before, changing only the pressure outlet boundary condition to 1 bar absolute pressure. In this case, the cavitation number was calculated to be equal to $C N=403$, the cavitation index $K=1.0025$, the Reynolds number $R e=11,700$ and the discharge coefficient $C_{d}=0.7318$.

\section{$\underline{\text { In-Nozzle Flow during Injection }}$}

The predicted liquid volume fraction is shown in Figure 13 and the corresponding velocity vectors in Figure 14. The difference between this and the previous high-pressure outlet test case is quite obvious straightaway. Even at $0.2 \mathrm{~ms}$ ASOI there are signs of cavitation right at the nozzle-hole entrance. In the ejected fuel region, there is a small area where the liquid volume fraction is smaller than 1 , implying the presence of gas. This gas is air, probably trapped there following the preset initial conditions. Some fluctuations can be seen again on the liquid-air interface, but the cone angle appears to be smaller than that of the previous case. Two large vortices that take up all the orifice volume are visible. They are quite strong and remain visible even outside the nozzle. This flow behaviour is different to the one noticed in the high-pressure outlet case, where two pairs of vortices were observed.

At maximum needle lift, a clear cavitation zone can be seen at the nozzle's entrance. The convection of some of the vapour downstream also illustrates the formation of a counter-rotating vortex pair in the same area. The vector plots indicate the existence of a second pair at the lower part of the orifice, as was also observed in the high-pressure outlet case. However, no cavitation is present there. The appearance of cavitation is manifested along with differences in the entire flow field. The jet's liquid core doesn't have the typical conical shape anymore and the cone angle is smaller than before. The flowfield is very far from hydraulic flip phenomena. The recirculation zone is very small, and far from reaching the nozzle exit. Higher injection pressures and a smaller length to 


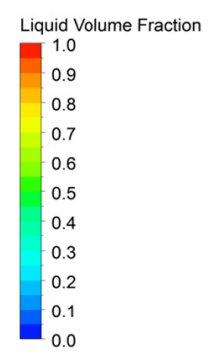

Time $=0.0009[\mathrm{~s}]$
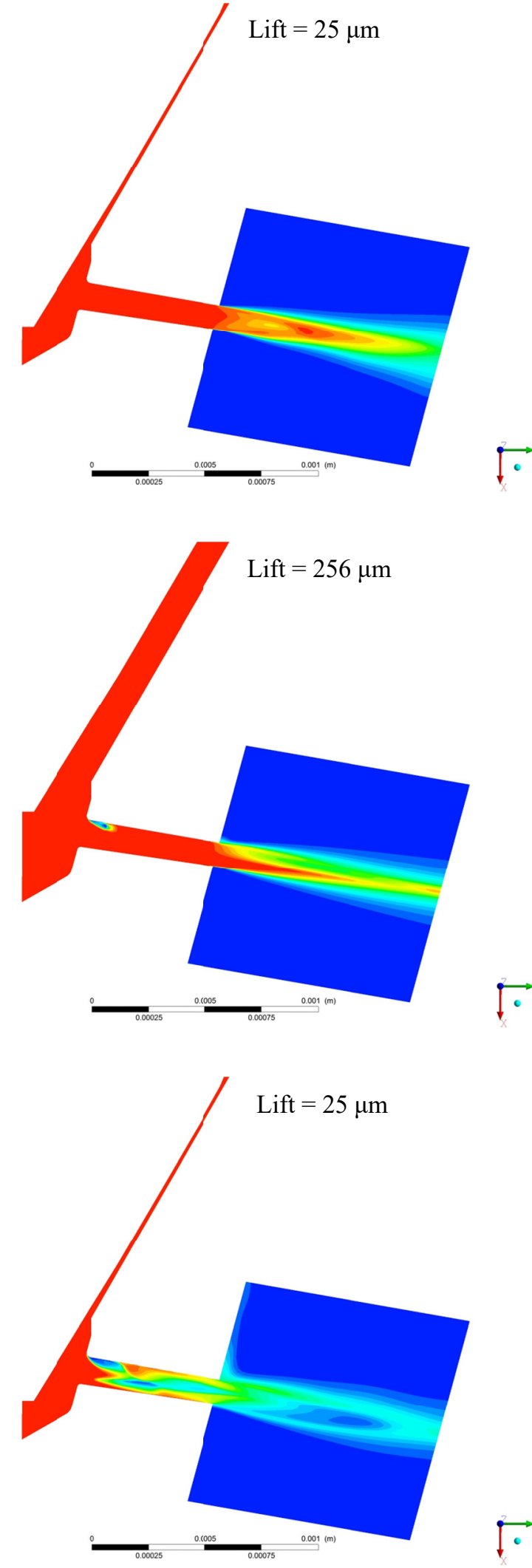

Time $=0.0025[\mathrm{~s}]$

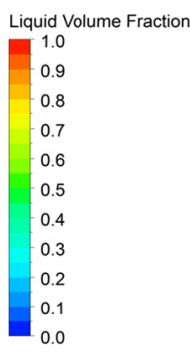

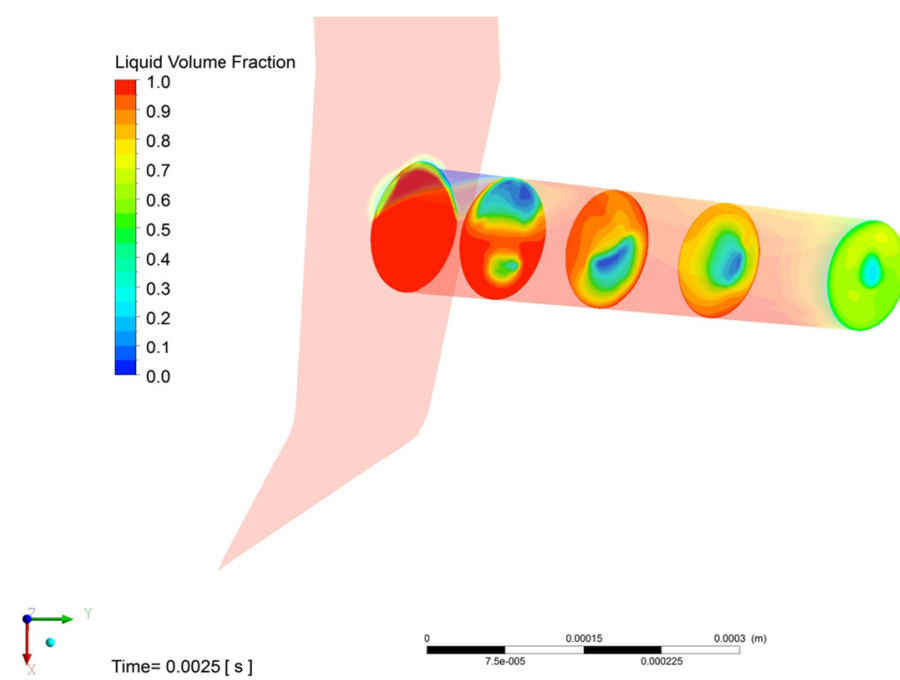

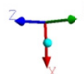

Figure 13. Liquid volume fraction for three time instances with ambient pressure 1 bar.

Page 12 of 18 


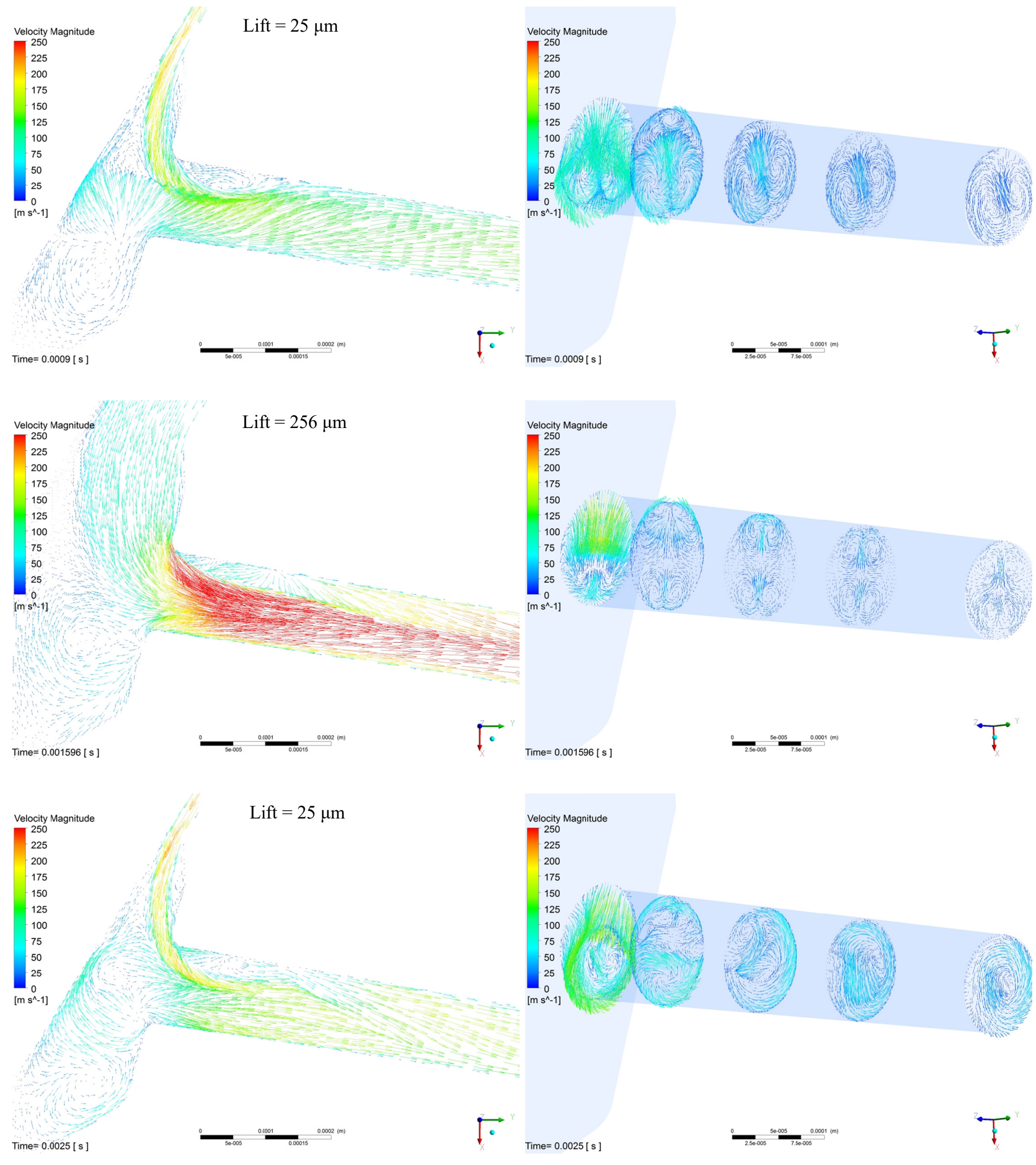

Figure 14. Velocity vectors tangential to the displayed planes, for three time instances with ambient pressure 1 bar.

Page 13 of 18 

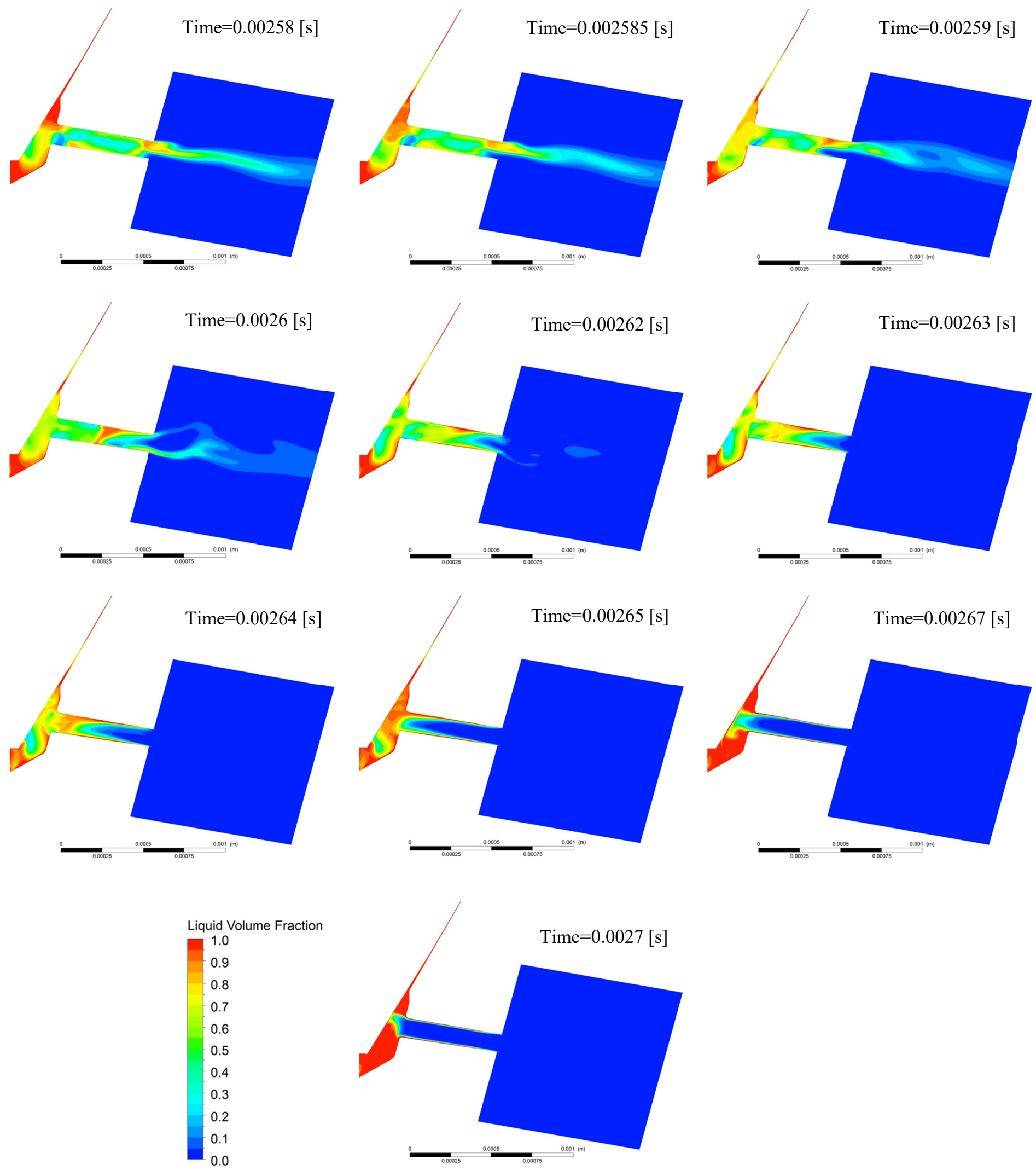

Figure 15. Evolution of the liquid volume fraction distribution, AEOI with ambient pressure 1 bar.

Page 14 of 18 
diameter ratio would be needed for this to happen. The clear presence of cavitation is in agreement with the findings of [45], according to which for $K=1.0025$ and $C_{d}=0.7318$ cavitating conditions were to be expected for $r / D=1 / 6$.

The needle closing stage is quite different to the high-pressure outlet case as well. With the needle being ready to close, the pressure drops in order to decelerate the flow and reaches values below the vapour pressure, so cavitation initiates. However, this is not restricted to the top corner of the nozzle orifice entrance, but the entire nozzle domain is associated with cavitation. The same behaviour was observed in the experiments of [10] where similar operating pressures were used, namely 300 bar injection pressure and atmospheric ambient pressure. In those experiments though, the injector used had a sharper inlet corner with a radius of curvature of 10 $\mu \mathrm{m}$ and a smaller inclination angle of $64^{\circ}$. These features promoted strongly the appearance of cavitation inside the nozzle. This behaviour can act as a possible explanation for the presence of large stagnant vapour bubbles at the beginning of consecutive injections that [9] and [10] noticed.

Below the main cavitation pocket there is another small cavitation region that interacts with the former. This is a second vapour region that has been created by flow separation and recirculation at the bottom part of the orifice's entrance and is linked to fluid that has been coming from the sac area and not directly from the needle seat region. The low lift of the needle has confined the available space inside the nozzle, upstream of the orifice entrance. This forces the fluid to a sharp turn. In combination with the high momentum, a small part of the fluid remains attached to the needle wall and enters the sac before turning towards the orifice. The same behaviour was noticed in [21] where a fixed needle lift of $30 \mu \mathrm{m}$ was employed; it is also noted that a higher injection pressure of 1600 bar was used in that study.

At the beginning of injection, while the needle was ascending, the momentum of the fluid was not very high, thus this did not result in the same type of flow-field observed at the closing stages. This is another indication of the hysteresis that exists between the opening and closing phases of the needle. The two aforementioned cavitation regions fill the nozzle with vapour that is then convected downstream of the nozzle exit. There is no clear, definite vortex shape, but there is intense swirl present in the nozzle hole. This is again in contrast to the observations at the same timing of the high-pressure outlet. This indicates not only the effect of the low pressure on the flow, but also the effect of cavitation and the large quantity of vapour that is created throughout.

\section{In-Nozzle Flow after the End of Injection}

On this occasion, when the needle closes, the ambient pressure is low enough to cause the liquid fuel to rupture in the nozzle, so a completely different flow field is developed to what observed in the previous case. The pressure drops quickly everywhere within the sac and orifice area, not just at a Page 15 of 18 recirculation zone region, as is the case during the main injection process. The same behaviour was noticed in [31]. The in-nozzle gas, being compressible, leads to different behaviour to what was observed in the case of the incompressible liquid phase that was present in the nozzle at the same time instance of the high outlet pressure case. The flow doesn't decelerate and, while it maintains it momentum and leaves the orifice, more vapour is created. The amount of time that is needed now for the flow to be brought to a halt is significantly larger. It takes about $120 \mu \mathrm{s}$, which is 6 times longer than before. The higher ambient pressure however acts as a force that drives the fluid towards the inner side of the nozzle. Therefore, when the flow decelerates and loses its momentum completely, it is pushed back inside the nozzle hole. Figure 15 shows the evolution of the flow after the end of injection. When the needle closes, the largest part of the nozzle is already filled with a mixture of liquid and vapour. Only the sac is filled with liquid, and the area right downstream of the needle seat. As the liquid-vapour mixture continues to exit the nozzle at decreasing velocity, air can be seen entering the nozzle from the lower part of the orifice exit. This is associated with pressure rise and vapour can be seen condensing. This is particularly evident at $0.0026 \mathrm{~s}$ and $0.00264 \mathrm{~s}$. The velocity of air that moves backwards into the orifice reaches $50 \mathrm{~m} / \mathrm{s}$. At the same time, the pressure inside the sac continues to drop, causing vaporization of the liquid located there; this gradually stops at $0.00265 \mathrm{~s}$. Then the procedure is reversed in the sac as well. At the end of these transient phenomena all the vapour has condensed back to liquid due to increased pressure. The orifice fills with air, except from a thin film of liquid that is left residing on the nozzle-hole walls. The sac volume, however, is still full of liquid. Figure 16 shows the velocity vectors $50 \mu$ s AEOI. It is clear that fluid is moving back, inside the nozzle, driven by the pressure in the injection chamber which is higher than the innozzle pressure. The scale of the legend has been capped to 10 $\mathrm{m} / \mathrm{s}$ to aid visualisation but values up to $30 \mathrm{~m} / \mathrm{s}$ were predicted, especially close to the nozzle's outlet.

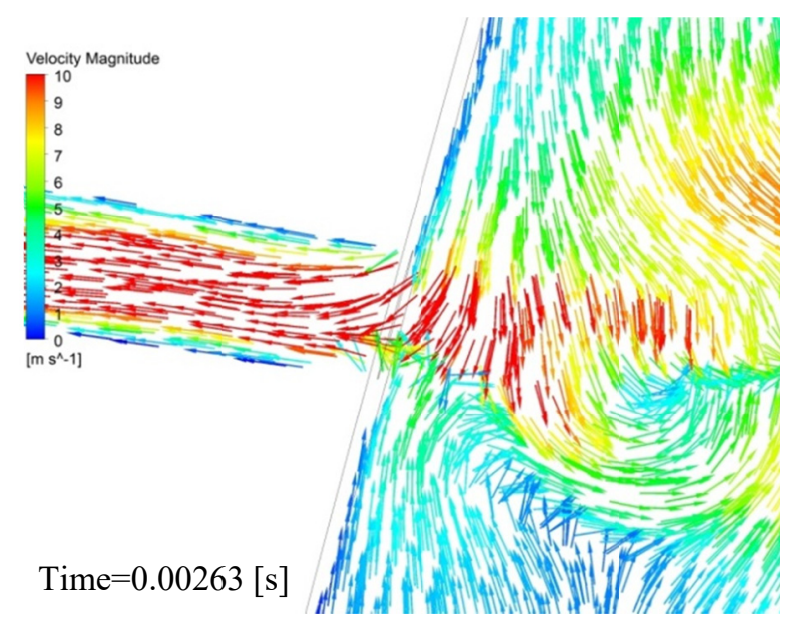

Figure 16. Velocity vectors of the nozzle backflow AEOI.

For completeness, it is also deemed necessary to comment on the effects of turbulence and potential laminarisation of the 
flow when the in-nozzle multi-phase phenomena are gradually brought to a rest in terms of advection processes. The simulations presented here were all performed with the turbulence model always enabled. It is very difficult to isolate a single value of Reynolds number that one could consider as a critical condition for full laminarisation under such transient conditions and with the presence of such complex multiphase phenomena and hysteresis effects. However, it is noted that the Reynolds number did not drop to values below 1000-2000 till after about $0.00265 \mathrm{~s}$ in Figure 15, i.e. towards the very end of the presented simulations. Specifically, despite the fact that the flow velocity gradually reduced inside the nozzle in the predominant direction of injection after needle closure, when the air back-filling process started, the velocity increased again in the opposite direction, as discussed earlier. The eddy viscosity in the nozzle never fell to levels lower than $\sim 5$ times the fluid's viscosity, even at the slowest bulk flow stages. It is clear that further work is needed in this area with various types of turbulence models and that this may also consider Schmidt and Prandtl number effects, especially in the presence of evaporation at higher temperatures inside the nozzle. Evaporation sub-modelling coupled to the cavitation methodology described here is currently work in progress by the authors and will be reported in a future publication.

\section{CONCLUSIONS}

CFD simulations of a vertical multi-hole injector were conducted for the full injection period and for a time period after needle closure till the flow became at rest. A part of the combustion chamber was attached to the nozzle outlet in order to investigate the flow in the near-nozzle outlet area and study the flow-field after the end of injection. A RANS formulation was used to account for turbulence. The VOF methodology with Diesel liquid fuel, diesel vapour and air was employed. A moving mesh methodology was also applied. The injection pressure was fixed at 400 bar, whilst two air chamber pressures (i.e. 'back' pressures) were studied, namely 60 bar and 1 bar. Initially, the methodology was validated by comparing the predicted flow rate against measurements of the real injector's flow rate. It was found that $k$ - $\omega$ SST model was in better agreement with the experimental data than the $k$ - $\varepsilon$ model, with differences of the order $3 \%$, hence this was adopted for the rest of the simulations. An optical nozzle test case from the literature was selected to validate the cavitation methodology. It was found that the Schnerr-Sauer model gave closer predictions than the Zwart-Gerber-Belami model to the imaged cavitation patterns of the published study over a range of Reynolds numbers, hence this was selected for all subsequent injector simulations. The main conclusions of the injector study can be summarized as follows:

- Hysteresis was noticed in the appearance of the flow-field between the needle opening and closing phases, indicating the importance of moving needle simulations.

- The effect of pressure at the outlet boundary was significant, resulting in cavitating or no-cavitating flow patterns for 1 bar and 60 bar, respectively, both during the injection event and after the end of it. This behaviour was consistent with findings reported in the literature about nozzles with similar geometric characteristics, discharge coefficients and cavitation indices.

- The area of separation at the nozzle hole inlet consisted of a pair of counter rotating vortices. These two vortices could be related to the creation of string cavitation but no phenomena of this type were captured by the modelling approach used here; further work would be needed in this area to resolve such phenomena.

- These counter-rotating vortices induced the creation of another pair of vortices inside the nozzle orifice. This was observed for 60 bar outlet pressure but was not observed at the beginning of the 1 bar outlet injection case, where only one pair was predicted. The abundance of vapour in the closing stages of the 1 bar outlet case had its own effect on the flow field where no coherent vortical structures appeared.

- The simulations indicated that after the end of injection, there is a quantity of fuel that leaves the nozzle. All fluid motion stopped $20 \mu \mathrm{s}$ AEOI, for the 60 bar outlet case (non-cavitating) and $120 \mu$ s for the 1 bar case (cavitating).

- For the case of 60 bar outlet, the amount of liquid fuel leaving the nozzle was minimal and appeared to be of 'dripping' nature. This meant that it would primarily remain inside the nozzle and either survive till the start of the next injection event or partially evaporate between injections depending on operating conditions. Additionally, the amount leaving at low velocity would not mix well with the chamber air and could contribute to increased unburned $\mathrm{HC}$ emissions.

- For the case of 1 bar outlet pressure, the nozzle almost emptied from liquid fuel at the end of injection and air was found to enter the orifice and move towards the sac at a speed of about $50 \mathrm{~m} / \mathrm{s}$. Such nozzle backfilling behaviour can be significant because at real engine conditions the nozzle hole may dry up fully by the hot incoming air, a phenomenon which could extend even into the sac region.

The implications of such differences in observed in-nozzle phenomena after the end of injection may well be important in the context of $\mathrm{HC}$ emissions, as well as mechanisms of deposit formation [46]. Therefore, the flow after the end of injection and during a whole engine cycle needs to be investigated with appropriate temperature predictions and evaporation submodelling coupled to the cavitation simulation methodology described here.

\section{REFERENCES}

1. Greeves, G., Khan, I.M., Wang, C.H.T and Fenne, I., 1978. Origins of Hydrocarbon emissions from diesel engines. SAE Paper 770259.

2. Birgel, A., Ladommatos, N., Aleiferis, P., Zuelch, S., Milovanovic, N., Lafon, V. and Richards, P., 2008.

Page 16 of 18 
Deposit Formation in the Holes of Diesel Injector

Nozzles: A Critical Review. SAE Paper 2008-01-2383.

3. Ford, H.S., Merion, D.F. and Hames, R.J., 1970.

Reducing Hydrocarbons and Odor in Diesel Exhaust by Fuel Injector Design. SAE Paper 700734.

4. Hawley J.G., Wallace F.J., Brace C.J., Horrocks R.W., 1998. Combustion Related Emissions in CI Engines, in Handbook of Air pollution from Internal Combustion Engines: Pollutant Formation and Control, pp. 280-357, Academic Press: USA

5. Andoh, H. and Shiraishi, K., 1986. Influence in injection and combustion phenomena by elimination of hole nozzle sac volume. SAE Paper 860416.

6. Soteriou, C., Andrews, R. and Smith, M., 1995. Direct injection diesel sprays and the effect of cavitation and hydraulic flip on atomization. SAE Paper 950080.

7. Bergwerk, W., 1959. Flow Pattern in Diesel Nozzle Spray Holes. Proceedings of the Institution of Mechanical Engineers, Vol. 173, pp. 655-660.

8. Chaves, H., Knapp, M., Kubitzek, A., Obermeier, F. and Schneider, T. 1995. Experimental Study of Cavitation in the Nozzle Hole of Diesel Injectors Using Transparent Nozzles. SAE Paper 950290.

9. Badock, C., Wirth, R., Fath and A., Leipertz, A., 1999. Investigation of cavitation in real size diesel injection nozzles. International Journal of Heat Fluid Flow, Vol. 20, pp. 538-544.

10. Mitroglou, N., McLorn, M., Gavaises, M., Soteriou, C. and Winterbourne, M., 2014. Instantaneous and ensemble average cavitation structures in Diesel micro-channel flow orifices. Fuel, Vol. 116, pp. 736-742.

11. Hayashi, T., Suzuki, M. and Ikemoto, M., 2013. Effects of internal flow in a diesel nozzle on spray combustion. International Journal of Engine Research, Vol. 14, pp. 646-654.

12. Greif, D. and Strucl, J., 2013. Numerical study of transient multi component fuel injection. SAE Paper 2013-01-2550.

13. Marcer, R., Le Cottier, P., Chaves, H., Argueyrolles, B., Habchi, C. and Barbeau, B., 2000. A validated numerical simulation of diesel injector flow using a VOF method. SAE Paper, 2000-01-2932.

14. Jia, M., Xie, M., Liu, H., Lam, W.H. and Wang, T., 2011. Numerical simulation of cavitation in the conical-spray nozzle for diesel premixed charge compression ignition engines. Fuel, Vol. 90, pp. 2652-2661.

15. Befrui, B., Spiekermann, P., Shost, M.A. and Lai, M.C., 2013. VOF-LES studies of GDi multi-hole nozzle plume primary breakup and comparison with imaging data. $25^{\text {th }}$ European Conference on Liquid Atomization and Spray Systems (ILASS-Europe 2013), Chania, Greece, 1-4 September 2013.

16. Befrui, B., Corbinelli, G., Hoffmann, G., Andrews, R.J. and Sankhalpara, S.R., 2009. Cavitation and hydraulic flip in the outward-opening GDi injector valve-group. SAE Paper 2009-01-1483.

17. Ming, P.J. and Zhang, X.Y., 2014. Numerical simulation of primary atomization with large eddy simulation method. $10^{\text {th }}$ International Conference on Heat Transfer, Fluid Mechanics and Thermodynamics, 14-16 July 2014, Orlando, Florida.

18. Arcoumanis, C., Gavaises, M., Nouri, J. M., AbdulWahab, E. and Horrocks, R.w, 1998. Analysis of the Flow in the Nozzle of a Vertical Multi-Hole Diesel Engine Injector. SAE Paper 980811.

19. Som, S., Aggarwal, S.K., El-Hannouny, E.M. and Longman, D.E., 2010. Investigation of Nozzle Flow and Cavitation Characteristics in a Diesel Injector. Journal of Engineering for Gas Turbines and Power, Vol. 132, p. 042802.

20. Mitroglou, N. and Gavaises, M., 2013. Mapping of cavitating flow regimes in injectors for medium -/heavyduty diesel engines. International Journal of Engine Research, 2013, Vol. 14, pp. 590-605.

21. Salvador, F.J., Martinez-Lopez, J., Caballer, M. and De Alfonso, C., 2013.Study of the influence of the needle lift on the internal flow and cavitation phenomenon in diesel injector nozzles by CFD using RANS methods. Energy Conversion and Management, Vol. 66, pp. 246-256.

22. Salvador, F.J., Martinez-Lopez, J., Romero, J.V. and Rosello, M.D., 2013. Computational study of the cavitation phenomenon and its interaction with the turbulence developed in diesel injector nozzles by Large Eddy Simulation (LES). Mathematical and Computer Modelling, Vol. 57, pp. 1656-1662.

23. Margot, X., Hoyas, S., Fajardo, P. and Patouna, S., 2011. CFD study of needle motion influence on the exit flow conditions of single-hole injectors. Atomization and Sprays, Vol. 21, pp. 31-40.

24. Gavaises, M., Papoulias, D., Giannadakis, E., Andriotis, A., Mitroglou, N. and Theodorakakos, A., 2008. Comparison of cavitation formation and development in Diesel VCO nozzles with cylindrical and converging tapered holes. Conference on Thermo- and Fluid Dynamic Processes in Diesel Engines (THIESEL), Valencia, Spain, 16-19 September 2008.

25. Margot, X., Garcia, A., Fajardo, P. and Patouna, S., 2010. Analysis of the cavitating flow in real size Diesel injectors with fixed and moving needle lift simulations. V European Conference on Computational Fluid Dynamics, (ECCOMAS CFD), Lisbon, Portugal, 14-17 June 2010.

26. He, Z., Zhong, W., Wang, Q., Jiang, Z. and Fu, Y., 2013. An investigation of transient nature of the cavitating flow in injector nozzles. Applied Thermal Engineering, Vol. 54, pp. 56-64.

27. Meister, G.F., Alajbegovic, A., Lai, M.C. and Yoo, J.H., 2002. Transient Simulation of DGI Engine Injector with Needle Movement. SAE Paper 2002-01-2663.

28. Xue, Q., Battistoni, M., Quan, S.P., Senecal, P.K., Pomraning, E., Schmidt, D.P. and Som, S., 2014. Eulerian modelling of fully-coupled diesel injector flow and spray. 26th Annual Conference on Liquid Atomization and Spray Systems, ILASS-Americas 2014, Portland, OR, May 2014.

29. Xue, Q., Som, S., Battistoni, M., Longman, D.E., Zhao, H., Senecal, P.K. and Pomraning, E., 2014. Three-

Page 17 of 18 
dimensional simulations of the transient internal flow in a diesel injector: Effects of needle movement. 26th Annual Conference on Liquid Atomization and Spray Systems, ILASS-Americas 2014, Portland, OR, May 2014.

30. Swantek, A.B., Duke, D., Tilocco, F.Z., Sovis, N., Powell, C.F. and Kastengren, A.L., 2014. End of injection, mass expulsion behaviors in single hole diesel fuel injectors. 26th Annual Conference on Liquid Atomization and Spray Systems, ILASS-Americas 2014, Portland, OR, May 2014.

31. Battistoni, M., Kastengren, A.L., Powel, C.F. and Som, S., 2014. Fluid dynamics modelling of End-of-Injection Process. 26th Annual Conference on Liquid Atomization and Spray Systems, ILASS-Americas 2014, Portland, OR, May 2014.

32. Ansys Fluent v14.5 documentation.

33. Launder, B.E. and Spalding, D.B., 1974. The numerical computation of turbulent flows. Computer Methods in Applied Mechanics and Engineering, Vol. 3, pp. 269-289.

34. Chang, K.C., Hsieh, W.D. and Chen, C.S, 1995. A modified low-Reynolds-number turbulence model applicable to recirculating flow in pipe expansion. Journal of Fluids Engineering, Vol. 117, pp. 417-423.

35. Menter, F.R., 1993. Zonal two equation k- $\omega$ turbulence models for aerodynamic flows. AIAA Paper 93-2906.

36. Muzaferija, S., Peric, M., Sames, P. and Schellin, T., 1998. "A Two-Fluid Navier-Stokes Solver to Simulate Water Entry". In Proc 22nd Symposium on Naval Hydrodynamics, Washington, DC. 277-289. 1998.

37. Schnerr, G.H. and Sauer, J., 2001. Physical and numerical modelling of unsteady cavitation dynamics. $4^{\text {th }}$ International Conference on Multiphase flow, New Orleans, USA, 2001.

38. Zwart, P.J., Gerber, A.G. and Belamri, T., 2004. A twophase flow model for predicting cavitation dynamics. $5^{\text {th }}$ International Conference on Multiphase Flow, Yokohama, Japan, 2004.

39. Arcoumanis, C., Gavaises, M., Flora, H. and Roth, H., 2001.Visualisation of cavitation in diesel engine injectors. Mecanique and Industries, Vol. 2, pp. 375-381.

40. Fimml, W., Chmela, F.G., Pirker, G. and Wimmer, A., 2010. Influence of cavitation in the injection nozzle on combustion in diesel engines. International Journal of Engine Research, Vol. 11, pp.375-390.

41. Reid, B.A., Gavaises, M., Mitroglou, N., Hargrave, G.K., Garner, C.P., Long, E.J. and McDavid, R.M., 2014. On the formation of string cavitation inside fuel injectors. Experiments in Fluids, Vol. 55, pp. 1662-1669.

42. Winklhofer, E., Kull, E., Kelz, E. and Morozov, A., 2001. Comprehensive hydraulic and flow field documentation in model throttle experiments under cavitation conditions. 17th Annual Conference on Liquid Atomization and Spray Systems, ILASS-Europe 2001, Zurich, Switzerland, 2-6 Sept. 2001.

43. Saha, K. and Li, X., 2013. Assessment of different cavitation models in mixture and Eulerian framework for two-phase flow in Diesel injectors. Proceedings of the ASME 2013 Internal Combustion Engine Division Fall
Technical Conference, Dearborn, Michigan, USA, 13-16 Oct. 2013.

44. Sou, A., Hosokawa, S. and Tomiyama, A., 2007. Effects of cavitation in a nozzle on liquid jet atomization. International Journal of Heat and Mass Transfer, Vol. 50, pp. 3575 0-3582.

45. He, Z., Zhong, W., Wang, Q., Jiang, Z. and Shao, Z., 2013.Effect of nozzle geometrical and dynamic factors on cavitating and turbulent flow in a diesel multi-hole injector nozzle. International Journal of Thermal Sciences, Vol. 70, pp. 132-143.

46. Birgel, A., Ladommatos, N., Aleiferis, P.G., Milovanovic, N., Lacey, P. and Richards, P., 2011. Investigations on deposit formation in the holes of Diesel injector nozzles. SAE International Journal of Fuels and Lubricants, Vol. 5, pp. 123-131, SAE Paper 2011-01-1924.

\section{CONTACT INFORMATION}

Dr. Pavlos Aleiferis

University College London

Department of Mechanical Engineering

Torrington Place, London WC1E 7JE, UK

Tel: +44-(0)20-76793862, Fax: +44-(0)20-73880180

E-mail: p.aleiferis@ucl.ac.uk

\section{ACKNOWLEDGEMENTS}

Financial support by the Engineering and Physical Science Research Council (EPSRC) is gratefully acknowledged. Delphi Diesel Systems are acknowledged for financial and technical support. The authors also acknowledge the use of University College London's Legion High Performance Computing Facility (Legion@UCL), and associated support services, in the completion of this work.

Page 18 of 18 